\title{
Antibacterial Fusion Proteins Enhance Moraxella catarrhalis Killing
}

\author{
Maisem Laabei ${ }^{1,2 t}$, Lucie Colineau ${ }^{1 t}$, Serena Bettoni ${ }^{1}, K^{2}$ arolina Maziarz ${ }^{1}$, David Ermert', \\ Kristian Riesbeck ${ }^{3}$, Sanjay Ram ${ }^{4}$ and Anna M. Blom ${ }^{1 *}$ \\ ${ }^{1}$ Division of Medical Protein Chemistry, Department of Translational Medicine, Faculty of Medicine, Lund University, Malmö, \\ Sweden, ${ }^{2}$ Department of Biology and Biochemistry, University of Bath, Bath, United Kingdom, ${ }^{3}$ Clinical Microbiology, \\ Department of Translational Medicine, Faculty of Medicine, Lund University, Malmö, Sweden, ${ }^{4}$ Division of Infectious \\ Diseases and Immunology, University of Massachusetts Medical School, Worcester, MA, United States
}

OPEN ACCESS

Edited by:

Seppo Meri,

University of Helsinki, Finland

Reviewed by:

Michael Kirschfink,

Heidelberg University, Germany

Elena Volokhina,

Radboud University Nijmegen Medical

Centre, Netherlands

*Correspondence:

Anna M. Blom

anna.blom@med.lu.se

${ }^{t}$ These authors have contributed equally to this work

Specialty section:

This article was submitted to

Molecular Innate Immunity,

a section of the journal

Frontiers in Immunology

Received: 04 April 2020

Accepted: 05 August 2020

Published: 02 September 2020

Citation:

Laabei M, Colineau L, Bettoni S,

Maziarz K, Ermert D, Riesbeck K,

Ram S and Blom AM (2020) Antibacterial Fusion Proteins Enhance

Moraxella catarrhalis Killing.

Front. Immunol. 11:2122.

doi: 10.3389/fimmu.2020.02122
Moraxella catarrhalis is a human-specific commensal of the respiratory tract and an opportunistic pathogen. It is one of the leading cause of otitis media in children and of acute exacerbations in patients with chronic obstructive pulmonary disease, resulting in significant morbidity and economic burden. Vaccines and new immunotherapeutic strategies to treat this emerging pathogen are needed. Complement is a key component of innate immunity that mediates the detection, response, and subsequent elimination of invading pathogens. Many pathogens including $M$. catarrhalis have evolved complement evasion mechanisms, which include the binding of human complement inhibitors such as $\mathrm{C} 4 \mathrm{~b}$-binding protein (C4BP) and Factor $\mathrm{H}(\mathrm{FH})$. Inhibiting $\mathrm{C} 4 \mathrm{BP}$ and $\mathrm{FH}$ acquisition by $M$. catarrhalis may provide a novel therapeutic avenue to treat infections. To achieve this, we created two chimeric proteins that combined the Moraxella-binding domains of C4BP and FH fused to human immunoglobulin Fcs: C4BP domains 1 and 2 and $\mathrm{FH}$ domains 6 and 7 fused to $\operatorname{lgM}$ and IgG Fc, respectively. As expected, FH6-7/lgG displaced $\mathrm{FH}$ from the bacterial surface while simultaneously activating complement via Fc-C1q interactions, together increasing pathogen elimination. C4BP1-2/lgM also increased serum killing of the bacteria through enhanced complement deposition, but did not displace C4BP from the surface of $M$. catarrhalis. These Fc fusion proteins could act as anti-infective immunotherapies. Many microbes bind the complement inhibitors $\mathrm{C} 4 \mathrm{BP}$ and $\mathrm{FH}$ through the same domains as $M$. catarrhalis, therefore these Fc fusion proteins may be promising candidates as adjunctive therapy against many different drug-resistant pathogens.

\section{Keywords: pathogen, Moraxella catarrhalis, fusion proteins, complement, antibacterial}

\section{INTRODUCTION}

Moraxella catarrhalis is a Gram-negative diplococcus which commonly colonizes the nasopharyngeal cavity of humans asymptomatically (1). However, in recent years, a greater appreciation of the virulent nature of this bacterium has emerged and $M$. catarrhalis is now considered an opportunistic pathogen $(1,2)$. M. catarrhalis is the third most common cause of

Abbreviations: AF, Alexa Fluor; BHI, brain-heart infusion; BSA, bovine serum albumin; C4BP, C4-binding protein; CCP, complement control protein; $\mathrm{CFSE}$, carboxyfluorescein succinimidyl ester; $\mathrm{CFU}$, colony forming unit; $\mathrm{CHO}$, Chinese hamster ovary; FH, factor H; gMFI, geometric mean fluorescence intensity; GVB, gelatin veronal buffer; Ig, immunoglobulin; MAC, membrane attack complex; NHS, normal human serum; OD, optical density; Usp, ubiquitous surface protein; WT, wild-type. 
acute sinusitis and otitis media in children and is responsible for a variety of lower respiratory tract infections in immunocompetent hosts and patients with chronic lung disease (2, 3). Rarely, M. catarrhalis can cause bacteraemia and pneumonia in immunocompromised individuals (4).

Humans have evolved a variety of mechanisms to evade infections caused by a multitude of microbial pathogens. The complement system represents an effective arm of innate immunity involved in detecting, labeling and eradicating potential microbial threats. Bacterial activation of complement is mediated by specific recognition molecules, which bind to conserved structures on the bacterial surface, initiating an enzymatic cascade resulting in the formation of the C3 convertases and cleavage of $\mathrm{C} 3$, the central protein of the complement cascade $(5,6)$. A strong activator of the classical pathway is the recognition subunit of the $\mathrm{C} 1$ complex, $\mathrm{Clq}$ (7). C1q interacts with high avidity with the Fc region of clustered immunoglobulin (Ig)Gs or multivalent IgM molecules and in conjunction with serine proteases, C1r and C1s, initiates proteolytic events resulting in C3 convertase formation (7). C3 can be cleaved into multiple fragments with opsonic properties and when deposited on the microbial surface, can interact with complement receptors expressed on the surface of professional phagocytes culminating in uptake and destruction of the pathogen (8). Further activation and processing of C3 forms C5 convertases, that cleave $\mathrm{C} 5$ into $\mathrm{C} 5 \mathrm{a}$, a potent chemoattractant, and $\mathrm{C} 5 \mathrm{~b}$, an essential building block of the membrane attack complex (MAC). Interaction of $\mathrm{C} 5 \mathrm{~b}$ with complement proteins C6 through $\mathrm{C} 9$ results in formation and insertion of MAC leading to a reduction in membrane potential and bacterial lysis of Gram-negative bacteria $(5,6)$.

To prevent complement destruction of host cells, a suite of soluble and cell surface regulators maintain complement homeostasis (9). Two soluble proteins, Factor $\mathrm{H}(\mathrm{FH})$ and $\mathrm{C} 4 \mathrm{~b}-$ binding protein (C4BP) are pivotal for preventing unwanted complement activation, both exerting their influence at the level of C3 convertase inhibition (9-11). FH is the major soluble inhibitor of the alternative pathway (AP), binds to $\mathrm{C} 3 \mathrm{~b}$ via complement control protein (CCP) domains 1-4 and accelerates the decay of the alternative C3 convertase while also acting as a cofactor for the serine protease, factor I mediated inactivation of C3b $(9,10)$. C4BP is the major inhibitor of the classical and lectin pathways, interacting with and limiting the function of complement protein $\mathrm{C} 4 \mathrm{~b}(9,11)$. In similar fashion to $\mathrm{FH}, \mathrm{C} 4 \mathrm{BP}$ acts as a cofactor for both FI proteolysis of cell-bound and soluble $\mathrm{C} 4 \mathrm{~b}$, disrupting formation of the classical C3 convertase $(9,11)$ and fluid phase C3b inhibiting AP activity (12). Furthermore, C4BP can accelerate the decay of formed classical pathway C3 convertase (11).

The success of any disease-causing organism depends on its ability to resist host immunity (13-15). As $\mathrm{FH}$ and C4BP are soluble proteins, a wide variety of pathogens have evolved mechanisms to bind and recruit these proteins to their surface, thus disrupting complement deposition $(13,16)$. Most bacteria recruit FH through CCP domains 6-7 and 18-20, thereby permitting $\mathrm{FH}$ domains $1-4$ to inhibit complement $(10,15)$. Pathogen binding of C4BP is generally associated with
CCP1-3, which is also responsible for $\mathrm{C} 4 \mathrm{~b}$ and $\mathrm{C} 3 \mathrm{~b}$ binding $(11,15)$. However, C4BP is a multimeric protein with seven identical alpha chains, which permits its simultaneous binding to different ligands while maintaining complement inhibitory activity $(11,15)$.

Infections are primarily curtailed by antibiotics or vaccines. In recent years, antibiotic resistance has become a major health problem globally, with the proliferation of multidrug-resistant bacteria (17). Development of new antibiotics and vaccines does not appear to meet the current medical demand, therefore new antimicrobial approaches are urgently needed. Chimeric proteins that fuse pathogen binding domains of either $\mathrm{FH}$ (CCPs 6-7) of the Fc region of human IgG (FH6-7/IgG) or C4BP (CCPs 1-2) fused to the constant domains $\mathrm{CH} 2, \mathrm{CH} 3$, and $\mathrm{CH} 4$ of IgM (C4BP1-2/IgM) resulting in a hexavalent chimeric protein have been developed as alternative strategies to control infection $(18,19)$. The net result is displacement of complement inhibitors from the bacterial surface with simultaneous complement activation via $\mathrm{Fc}-\mathrm{Clq}$ interaction, which increases pathogen elimination. This approach has shown promise in enhancing killing of Non-typeable Haemophilus influenzae (NTHi) (20), Neisseria meningitidis (18), Neisseria gonorrhoeae $(19,21)$, and Streptococcus pyogenes (22). In this study we tested the bactericidal activity of both fusion proteins against M. catarrhalis.

\section{MATERIALS AND METHODS}

\section{Bacteria and Cell Line Culture Conditions}

Bacteria used in this study were $M$. catarrhalis strain RH4 (23), isogenic mutants of RH4 devoid of UspA1 ( $\triangle u s p A 1)$, UspA2 ( $\triangle u s p A 2)$, and both UspA1 and UspA2 ( $\Delta u s p A 1 \Delta u s p A 2)(24)$, and clinical isolates KR473, KR478, KR479, KR485, KR502, KR507, KR508, KR530, KR533, KR488, KR504, KR506, KR531, KR539, KR540, KR477, KR480, KR482, KR510, KR515, and KR527 (25). All strains of $M$. catarrhalis were routinely cultured on chocolate blood agar and grown overnight at $37^{\circ} \mathrm{C}$ with $5 \% \mathrm{CO}_{2}$. Prior to experiments, bacteria were sub-cultured from overnight plates and streaked onto new chocolate blood agar plates and grown for 6-8 h. Bacteria were scraped from plates and resuspended into freezing medium [25\% brain-heart infusion (BHI)/glycerol], and subsequently aliquoted and stored at $-80^{\circ} \mathrm{C}$ until use.

Staphylococcus aureus strain USA300 JE2 were grown in tryptic soy broth at $37^{\circ} \mathrm{C}$ with shaking $(200 \mathrm{rpm})$. Overnight cultures were normalized to an $\mathrm{OD}_{600 \mathrm{~nm}}=0.1$ in fresh medium and grown under the same conditions until an $\mathrm{OD}_{600 \mathrm{~nm}}=0.3-$ 0.4 , corresponding to mid-exponential phase of growth. Bacteria were centrifuged and washed once in sterile PBS and normalized to an $\mathrm{OD}_{600 \mathrm{~nm}}=1$ which equates to $1-2 \times 10^{8} \mathrm{CFU} / \mathrm{ml}$.

FreeStyle Chinese hamster ovary (CHO) S suspension cells (Life Technologies), grown in FreeStyle CHO expression medium supplemented with $8 \mathrm{mM}$ L-glutamine were used for the expression of FH6-7/IgG fusion protein as described (22). Cell cultures were grown in $250 \mathrm{ml}$ Erlenmeyer flasks at $37^{\circ} \mathrm{C}$ with $8 \% \mathrm{CO}_{2}$ with shaking $(130 \mathrm{rpm})$. Adherent $\mathrm{CHO}$ cells grown 
in serum-free OptiMEM Glutamax medium were used for the expression of C4BP1-2/IgM as described (19). For expression and collection of C4BP1-2/IgM fusion protein, adherent cells were washed twice in PBS and grown in Opti-MEM for $48 \mathrm{~h}$. Following $48 \mathrm{~h}$, cells were washed and grown in $\mathrm{CHO}$ expression medium for $24 \mathrm{~h}$ and this procedure repeated for 15 days.

\section{Purification of Fusion Proteins}

Fusion protein FH6-7/IgG were expressed in $\mathrm{CHO}$ cells and purified on protein $A / G$ columns as described previously (22). Bound proteins were eluted using $0.1 \mathrm{M}$ glycine, $\mathrm{pH}=2.7$. Protein eluate was dialyzed three time in $\mathrm{PBS}$ at $4^{\circ} \mathrm{C}$ and protein concentrations calculated on aBio photomoter. The C4BP12/IgM fusion protein was purified using a HiTrap Normal human serum (NHS)-activated Sepharose $5 \mathrm{ml}$ column coupled with antibody MK104, which recognizes the CCP-1 domain of C4BP as described previously (19).

\section{Binding of Fusion Proteins to M. catarrhalis}

Moraxella catarrhalis glycerol stocks were thawed at $37^{\circ} \mathrm{C}$ for $30 \mathrm{~min}$ and washed once in PBS for $5 \mathrm{~min}$ at $5000 \times \mathrm{g}$. Bacteria were normalized to $\mathrm{OD}_{600} \mathrm{~nm}$ of 1 , stained with carboxyfluorescein succinimidyl ester (CFSE, $10 \mu \mathrm{M}$ ) for $30 \mathrm{~min}$ at $37^{\circ} \mathrm{C}$ and washed once in PBS, for gating in flow cytometry assays. Bacterial concentrations were adjusted to an $\mathrm{OD}_{600} \mathrm{~nm}$ of 0.5 in PBS and thereafter $50 \mu \mathrm{l}$ was mixed with $50 \mu \mathrm{l}$ of increasing concentrations of fusion proteins for $30 \mathrm{~min}$ at $37^{\circ} \mathrm{C}$ in a covered V-bottomed 96 well plate. Bacteria were centrifuged for $5 \mathrm{~min}$ at $5000 \times g$ at room temperature (RT) and washed once in PBS. To detect FH6-7/IgG binding to $M$. catarrhalis, bacteria were stained with Alexa Fluor (AF) - 488 goat anti-human IgG (1:1000; Invitrogen) in $1 \%(\mathrm{w} / \mathrm{v}) \mathrm{BSA} / \mathrm{PBS}$ for $30 \mathrm{~min}$ at $\mathrm{RT}$. To detect C4BP1-2/IgM binding, bacteria were stained with polyclonal rabbit anti-human IgM (1:1000; Dako) for 30 min at RT. Bacteria were centrifuged and washed once in $1 \%(\mathrm{w} / \mathrm{v})$ BSA/PBS and for C4BP1-2/IgM detection, followed by a secondary antibody staining (AF-647 goat anti-rabbit, 1:1000; Invitrogen) for $30 \mathrm{~min}$ in the dark. For both fusion proteins, following $\mathrm{Ab}$ staining, bacteria were centrifuged and washed once in $1 \%(\mathrm{w} / \mathrm{v}) \mathrm{BSA} / \mathrm{PBS}$, resuspended in $150 \mu \mathrm{l}$ PBS and deposited fusion proteins were assessed using a CytoFLEX flow cytometer. Bacteria incubated without fusion protein was used as a negative control. CFSEstained and non-stained bacteria were used for gating purposes and a minimum of 20,000 events were examined. To assess the binding of C4BP-IgM in the presence of serum, the fusion protein was labeled with AF 488 using AF 488 microscale labeling kit (A10235, Molecular Probes).

\section{Serum Bactericidal Assays}

Bacteria were prepared as described in bacteria-fusion protein binding section, with the omission of the CFSE staining. NHS was prepared from freshly drawn blood with informed consent from at least eight healthy volunteers as described (26) and in accordance with the recommendations of the ethical committee at Lund University (Permit 2017/582) and the Declaration of
Helsinki (27). Bacteria were normalized to $\mathrm{OD}_{600} \mathrm{~nm}$ of 0.05 . Fifty microliters of bacteria were incubated in the presence or absence of $40 \mu \mathrm{l}$ of fusion protein (final concentration $50 \mu \mathrm{g} / \mathrm{ml}$ ) for $30 \mathrm{~min}$ at $37^{\circ} \mathrm{C}$ in $\mathrm{GVB}^{++}$buffer $[5 \mathrm{mM}$ veronal buffer $\mathrm{pH} 7.3,0.1 \%(w / v)$ gelatin, $140 \mathrm{mM} \mathrm{NaCl}, 1 \mathrm{mM} \mathrm{MgCl}$, and $0.15 \mathrm{mM} \mathrm{CaCl}_{2}$ ]. After $30 \mathrm{~min}, 10 \mu \mathrm{l}$ of pooled NHS was added and incubated with bacteria for a further $30 \mathrm{~min}$ at $37^{\circ} \mathrm{C}$. Alternatively, bacteria and fusion protein in $\mathrm{GVB}^{++}$buffer $(0-$ $100 \mu \mathrm{g} / \mathrm{ml}$ ) in addition to serum were added simultaneously and incubated for $30 \mathrm{~min}$ at $37^{\circ} \mathrm{C}$. For calculation of bacteria survival, samples of bacteria were removed at time 0 and time $30 \mathrm{~min}$ following incubation at $37^{\circ} \mathrm{C}$, serially diluted in PBS and spread onto chocolate agar plates for colony enumeration after growth overnight at $37^{\circ} \mathrm{C}$ with $5 \% \mathrm{CO}_{2}$. As a control heat-inactivated serum was used following treatment at $56^{\circ} \mathrm{C}$ for $30 \mathrm{~min}$.

\section{Binding Competition Experiments}

Bacteria were thawed, washed once in PBS and normalized to an $\mathrm{OD}_{600} \mathrm{~nm}$ of 0.5 . Two experimental protocols were utilized: (1) Bacteria were pre-incubated with varying concentrations of either FH6-7/IgG or C4BP1-2/IgM in $\mathrm{GVB}^{++}$buffer for $30 \mathrm{~min}$ at $37^{\circ} \mathrm{C}$. Following incubation, NHS treated with the complement C5 inhibitor OmCI $(10 \mu \mathrm{g} / \mathrm{ml} ; 0.625 \mu \mathrm{M}$ ) (expression vector obtained from Swedish Orphan Biovitrum) (28) on ice for $30 \mathrm{~min}$ was added to a final concentration of $10 \%$ and incubated at $37^{\circ} \mathrm{C}$ for $30 \mathrm{~min}$; (2) Bacteria, FH6-7/IgG fusion protein (at a final concentration of 0,50 , or $100 \mu \mathrm{g} / \mathrm{ml}$ ) and OmCI-treated NHS (final concentration of 10\%) were added simultaneously and incubated at $37^{\circ} \mathrm{C}$ for $30 \mathrm{~min}$. Following incubation, bacteria were centrifuged and washed once in $1 \%(w / v)$ BSA/PBS. To determine serum FH binding, biotinylated $\mathrm{Ab}$ specific to CCP domain 5 of FH (MRC OX-24-biotin; 1:500) was used for $30 \mathrm{~min}$ at RT. Bacteria were washed once in $1 \%(\mathrm{w} / \mathrm{v}) \mathrm{BSA} / \mathrm{PBS}$ and stained with AF647-streptavidin (1:1000; Invitrogen) in the dark for $30 \mathrm{~min}$ at RT. To determine serum C4BP binding, $\mathrm{Ab}$ specific to CCP domain 4 of the alpha chains of C4BP (MK67; 1:1000) (29) was used for 30 min at RT. Bacteria were washed once in $1 \%(\mathrm{w} / \mathrm{v}) \mathrm{BSA} / \mathrm{PBS}$ and stained with AF-647 goat anti-mouse (1:1000; Invitrogen). Bacteria were centrifuged and washed once in $1 \%(\mathrm{w} / \mathrm{v}) \mathrm{BSA} / \mathrm{PBS}$, resuspended in $150 \mu \mathrm{l}$ $\mathrm{PBS}$ and serum $\mathrm{FH}$ or $\mathrm{C} 4 \mathrm{BP}$ binding were assessed using a CytoFLEX flow cytometer.

\section{Complement Deposition Assays}

Bacteria were prepared as described in the binding assay section. For detection of complement components C3d and iC3b, bacteria, fusion protein, and OmCI-treated NHS (final concentration of 5\%) were incubated for $30 \mathrm{~min}$ at $37^{\circ} \mathrm{C}$. Bacteria were centrifuged and washed once in PBS and stained with either a monoclonal murine anti-human C3d Ab (1:1000, Quidel, A207) or a monoclonal murine anti-human iC3b Ab (1:1000, Quidel, A209) in 1\% (w/v) BSA/PBS for $30 \mathrm{~min}$ at RT. For detection of MAC, NHS at a final concentration of $10 \%$ was used and bacteria incubated for $20 \mathrm{~min}$ at $37^{\circ} \mathrm{C}$. Following washing, bacteria were stained with monoclonal mouse anti-human C9 neoantigen (1:1000, Hycult, aE11) for 30 min at RT. Bacteria were centrifuged and washed once in PBS followed by staining with AF-647 goat 
anti-mouse, 1:1000; Invitrogen) for $30 \mathrm{~min}$ in the dark at RT. Bacteria were centrifuged and washed once in PBS, resuspended in $150 \mu \mathrm{l}$ of PBS and deposited complement components detected using a CytoFLEX flow cytometer (Beckman Coulter).

\section{Whole Blood Survival and Phagocytosis Assay}

Moraxella catarrhalis were prepared as described in the binding assay section. S. aureus were grown as described on the bacteria section. Bacteria were normalized to $\mathrm{OD}_{600 \mathrm{~nm}}$ of 1 , stained with CFSE $(10 \mu \mathrm{M})$ for $30 \mathrm{~min}$ at $37^{\circ} \mathrm{C}$ and washed once in PBS.

Human blood was taken from healthy volunteers and treated with lepirudin (Refludan $50 \mu \mathrm{g} / \mathrm{ml}$; Celgene). Five hundred microliters of blood were incubated for $30 \mathrm{~min}$ with $1 \mu \mathrm{M}$ OmCI, $10 \mu \mathrm{M}$ cytochalasin D (Sigma-Aldrich) or both, on an end-over-end shaker at $37^{\circ} \mathrm{C}$ and $5 \% \mathrm{CO}_{2}$. Approximately $5 \times 10^{5} \mathrm{CFU}$ of CFSE-stained bacteria were added to blood, and blood suspensions were incubated on a shaker at $37^{\circ} \mathrm{C}$ and $5 \% \mathrm{CO}_{2}$.

To assess the survival of bacteria in blood, at specific time points a sample of the suspension was collected, serially diluted in PBS and plated onto chocolate agar plates (M. catarrhalis) or blood agar plates (S. aureus). Agar plates were incubated overnight at $37^{\circ} \mathrm{C}$ and $5 \% \quad \mathrm{CO}_{2}$ and $\mathrm{CFU} / \mathrm{mL}$ determined following enumeration of surviving bacteria.

To assess the phagocytosis of bacteria, at specific time points a sample of the suspension was collected, red blood cells lysis was performed by addition of water followed by addition of $10 \times$ PBS to restore osmotic pressure. Cells were centrifuged at $300 \mathrm{~g}$ for $5 \mathrm{~min}$ and fixed by incubation in $4 \%$ paraformaldehyde in PBS for $15 \mathrm{~min}$ at RT. Cells were stained with anti-CD14 APC antibody (Beckman Coulter) for $30 \mathrm{~min}$, washed once in PBS and resuspended in PBS for analysis using a CytoFLEX flow cytometer.

\section{Statistical Analysis}

To examine differences between experimental groups, a one-way or two-way ANOVA was used (GraphPad Prism v7.0); a $p$-value was $<0.05$ was considered statistically significant. The $p$-values shown in figure legends represent the post hoc tests.

\section{RESULTS}

\section{Fusion Proteins Bind to M. catarrhalis}

The fusion protein FH6-7/IgG was created by combining the CCP6 and CCP7 domains of FH with the Fc region of human IgG (Figure 1A). C4BP1-2/IgM was made by fusing the CCP1 and CCP2 domains of C4BP together with the constant domains $\mathrm{CH} 2, \mathrm{CH} 3$, and $\mathrm{CH} 4$ of human IgM (Figure 1B). C4BP1-2/IgM forms multimers similarly to IgM, hexamers (dodecamers of C4BP CCPs $1-2 ; \sim 80 \%$ ) or pentamers (decamers of C4BP CCPs $1-2$; 20\%) (19).

To understand whether fusion proteins (FH6-7/IgG and C4BP1-2/IgM) could be used as alternative treatment strategies, we first explored whether these proteins could bind the wellcharacterized M. catarrhalis strain RH4. M. catarrhalis is known to bind both soluble complement inhibitors, $\mathrm{FH}$ and C4BP $(24,30)$. Fusion proteins incubated with bacteria over a range of concentrations confirmed that $M$. catarrhalis interacts with FH6-7/IgG (Figure 1C) and C4BP1-2/IgM (Figure 1D) in a dose-dependent fashion.

The ubiquitous surface proteins (Usp) A1 and A2 are highmolecular weight proteins that are abundantly expressed at the surface of $M$. catarrhalis (31). UspA2 plays an important role in immunity evasion as it can bind the complement inhibitors C4BP (24), vitronectin (32) and plasminogen (33). To test the possibility that the fusion proteins bind $M$. catarrhalis through UspA1 and/or UspA2, we used mutants lacking UspA1 and/or UspA2. The binding of FH6-7/IgG was reduced in the single mutant $\triangle u s p A 2$ and the double mutant $\triangle u s p A 1 \Delta u s p A 2$, but not in $\Delta u s p A 1$, compared to the wild-type (WT) strain (Figure 1E). A similar observation was made when assessing the binding of whole FH (Figure 1G), suggesting that the fusion protein FH6-7/IgG, like FH, binds partly through UspA2. The binding of C4BP1-2/IgM was unchanged in $\triangle u s p A 1$ compared to WT $M$. catarrhalis, but almost completely abrogated in $\triangle u s p A 2$ and $\triangle u s p A 1 \triangle u s p A 2$ (Figure 1F), similar to the binding of C4BP from NHS (Figure 1H). Therefore, the fusion protein C4BP1-2/IgM binds $M$. catarrhalis mainly through UspA2.

\section{FH6-7/lgG but Not C4BP1-2/lgM Prevents Binding and Outcompetes Respective Soluble Complement Inhibitor}

We investigated the interplay between fusion proteins and the ability of $M$. catarrhalis to recruit FH and C4BP to the bacterial surface. Firstly, we pre-incubated $M$. catarrhalis strain RH4 with increasing concentrations of $\mathrm{FH} 6-7 / \mathrm{IgG}$ or $\mathrm{C} 4 \mathrm{BP} 1-2 / \operatorname{IgM}$ followed by the addition of OmCI-treated serum as a source of $\mathrm{FH}$ and C4BP. After incubation we examined the amount of $\mathrm{FH}$ or C4BP binding with antibodies specific to CCP domains present in serum-derived $\mathrm{FH}$ and $\mathrm{C} 4 \mathrm{BP}$, but not in the respective Fc fusion proteins. Preincubation of RH4 with FH6-7/IgG with concentrations as low as $1.5 \mu \mathrm{g} / \mathrm{ml}$ resulted in a significant reduction in $\mathrm{FH}$ binding from serum with an inverse correlation between FH6-7/IgG and FH binding continuing in a dosedependent fashion (Figure 2A). Next, we assessed whether FH67/IgG could outcompete serum $\mathrm{FH}$ in binding to $M$. catarrhalis when added concurrently with NHS. Under these experimental settings, FH6-7/IgG also outcompeted FH binding from serum (Figure 2B). In contrast, no difference was observed in serum $\mathrm{C} 4 \mathrm{BP}$ binding when bacteria were pre-incubated with increasing concentrations of C4BP1-2/IgM (Figure 2C). These data show that FH6-7/IgG can successfully displace FH at the surface of $M$. catarrhalis, while C4BP1-2/IgM does not out-compete serum C4BP, suggesting that C4BP binds the bacteria with a higher affinity than the fusion protein. Based on the observation that C4BP-IgM does not outcompete C4BP for binding to the bacteria, we tested whether C4BP-IgM could bind bacteria in the presence of serum (OmCI-treated). We found that the binding of C4BPIgM is decreased when increasing concentrations of serum are added at the same time (Figure 2D), but there seems to be still 
A

$\begin{array}{lll}\text { IgG Factor H } & \text { FH6-7/lgG }\end{array}$

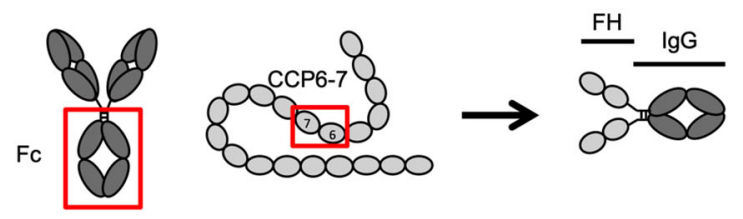

B

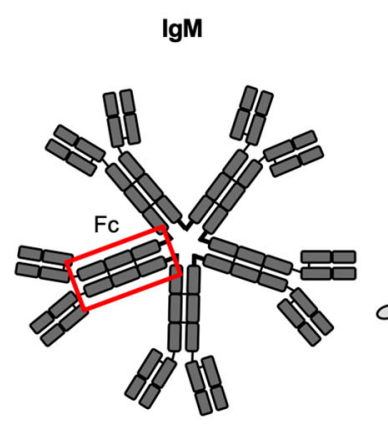

C

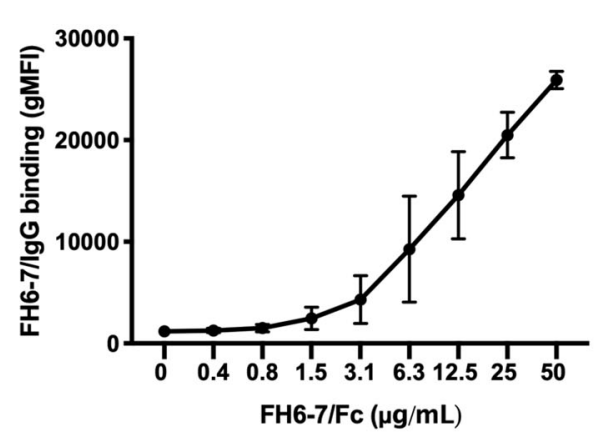

D

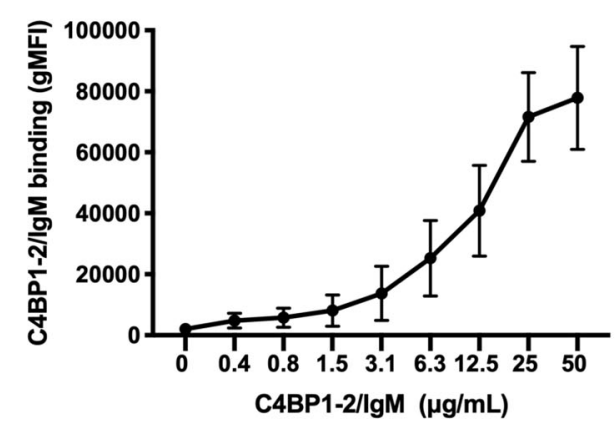

E

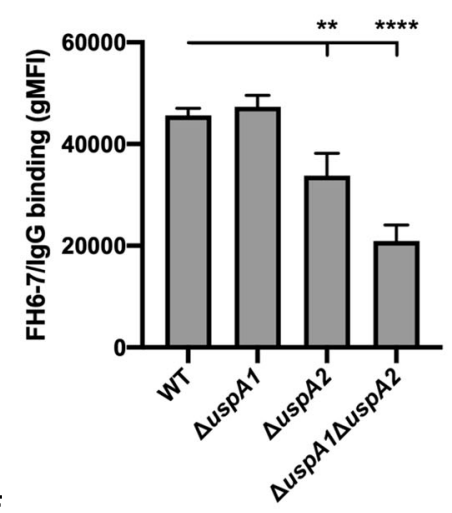

$\mathbf{F}$

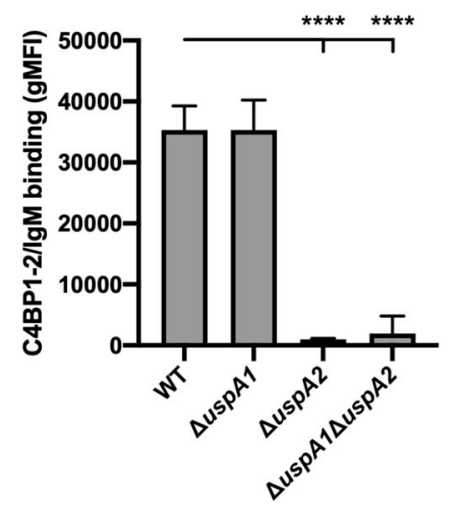

C4BP1-2/lgM

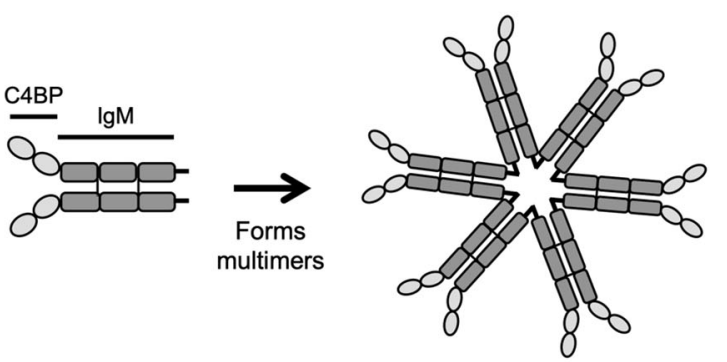

G

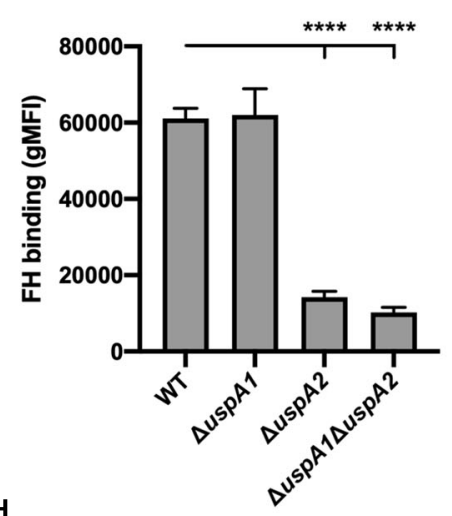

H

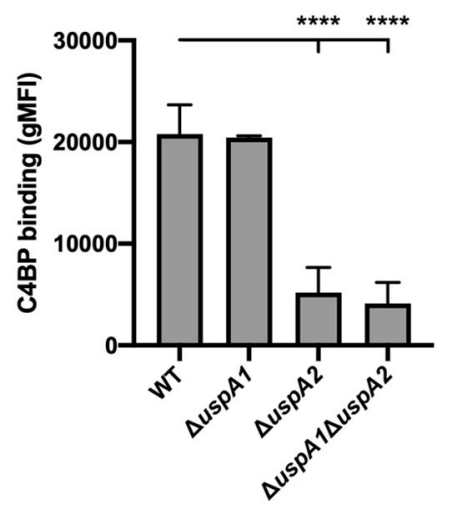

FIGURE 1 | FH 6-7/lgG and C4BP1-2/lgM bind to M. catarrhalis. (A,B) Schematic representation of fusion proteins FH6-7/lgG and C4BP1-2/lgM, respectively. (C) Binding of FH6-7/lgG and (D) C4BP1-2/lgM to M. catarrhalis RH4 [wild-type (WT) reference strain] assessed by flow cytometry. (E-H) Binding of RH4 WT and isogenic mutants lacking uspA1 and/or uspA2 to (E) FH6-7/lgG, (F) C4BP1-2/lgM, (G) factor H (FH), and (F) C4b-binding protein (C4BP). Mean ( \pm SD) from three independent experiments are shown. Statistical significance of differences was calculated using one-way ANOVA with Dunnett's post-test $(\mathbf{E}-\mathbf{H}) ;{ }^{* *} p<0.01$ and ${ }^{\star \star \star *} p<0.0001$. 
A

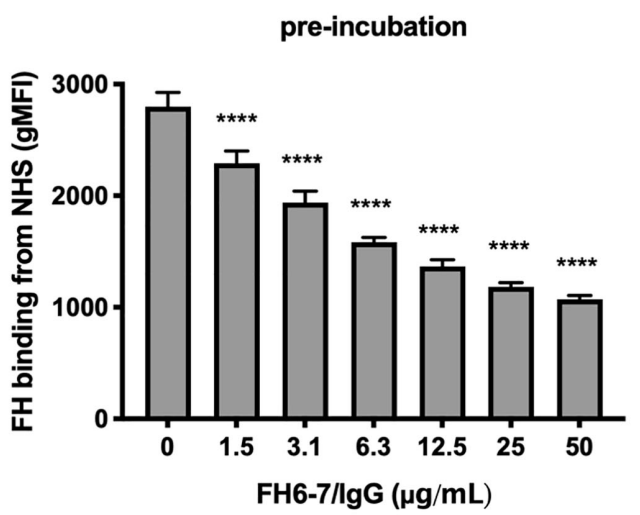

C

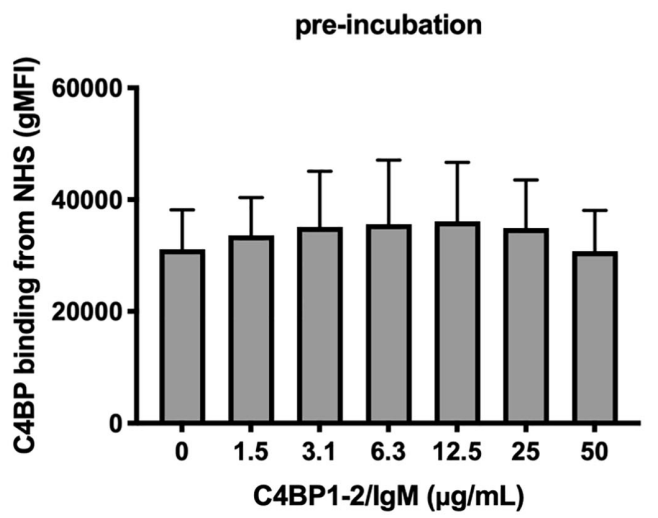

B

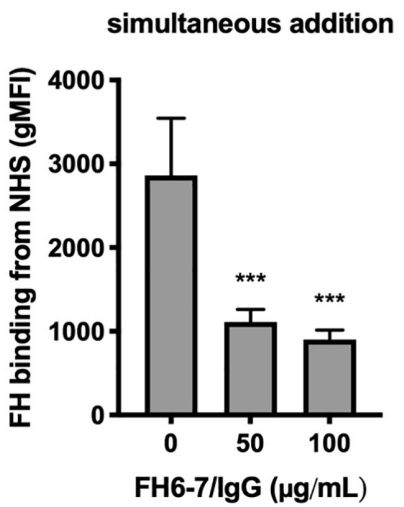

D

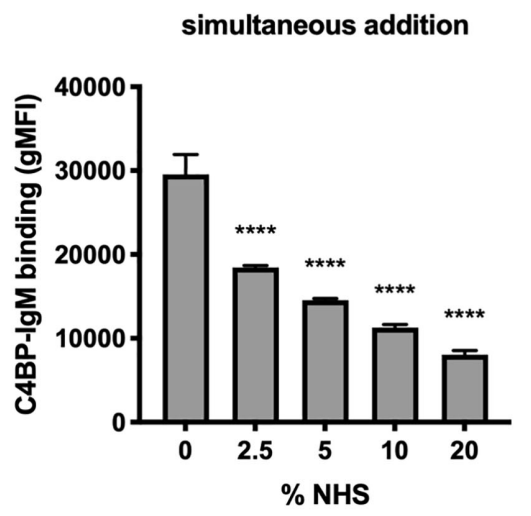

FIGURE 2 | FH6-7/lgG competes out serum FH, but C4BP1-2/lgM does not compete out serum C4BP. (A) M. catarrhalis were pre-incubated in increasing amounts of FH6-7/lgG, followed by the addition of OmCl-treated serum (C5-inhibitor). The binding of FH from NHS was assessed by flow cytometry using antibodies specific to domains present in serum derived FH but absent on the fusion proteins. (B) FH6-7/lgG and NHS were added simultaneously to the bacteria and binding of FH from NHS was assessed. (C) M. catarrhalis pre-incubated in increasing amounts of C4BP1-2/lgM, followed by OmCl-treated serum were tested for the binding of C4BP from NHS by flow cytometry using antibodies specific to domains present in serum derived C4BP but absent on the fusion proteins. (D) Alexa Fluor 488-labeled C4BP-IgM was added simultaneously with differing concentrations of OmCl-treated serum to bacteria to assess the binding of the fusion protein. Mean $( \pm \mathrm{SD})$ from three independent experiments are shown. Statistical significance of differences was calculated using one-way ANOVA with Dunnett's post-test; ${ }^{* * *} p<0.001$ and ${ }^{* * * *} p<0.0001$.

a significant binding in the presence of $10 \%$ NHS which is the amount used in serum bactericidal assays.

\section{Serum Bactericidal Activity Is Enhanced by Fusion Proteins}

Complement activation results in phagocytic clearance of bacteria as well as direct bacterial killing through the formation of lytic MAC. Gram-positive bacteria are not sensitive to MAC-mediated killing, but it plays a critical role against Gram-negative bacteria such as $M$. catarrhalis (34). In order to assess the respective roles of phagocytosis and MACmediated killing in clearance of $M$. catarrhalis, we employed a whole blood infection model, using human blood pre-treated with complement C5 inhibitor OmCI, phagocytosis inhibitor cytochalasin $\mathrm{D}$ or both. We observed that $M$. catarrhalis survival in whole blood is increased when complement is inhibited but not significantly changed when phagocytosis was inhibited (Figure 3A). However, phagocytosis of $M$. catarrhalis by granulocytes and monocytes remained unchanged by $\mathrm{OmCI}$ compared to untreated blood, while cytochalasin D inhibited phagocytosis as expected (Figure 3B). It is worth noting that this method does not distinguish between live and dead bacteria being taken up by phagocytes. This confirms that phagocytosis does not play a major role in $M$. catarrhalis killing in whole blood as it does not correlate with bacteria survival numbers: bacteria survive much better in OmCI-treated blood than untreated blood, however phagocytosis is unchanged. To confirm that our model works, and to highlight the difference between Gram-negative $M$. catarrhalis and a Gram-positive bacteria, we performed the same experiments in parallel with $S$. aureus. As expected, inhibition of phagocytosis increased the survival of $S$. aureus, while complement inhibition at the level of C5 did not (Figure 3C). Phagocytosis of S. aureus was similar to $M$. catarrhalis, as it was unchanged by OmCI but inhibited by cytochalasin D (Figure 3D). Altogether, this experiment confirms 

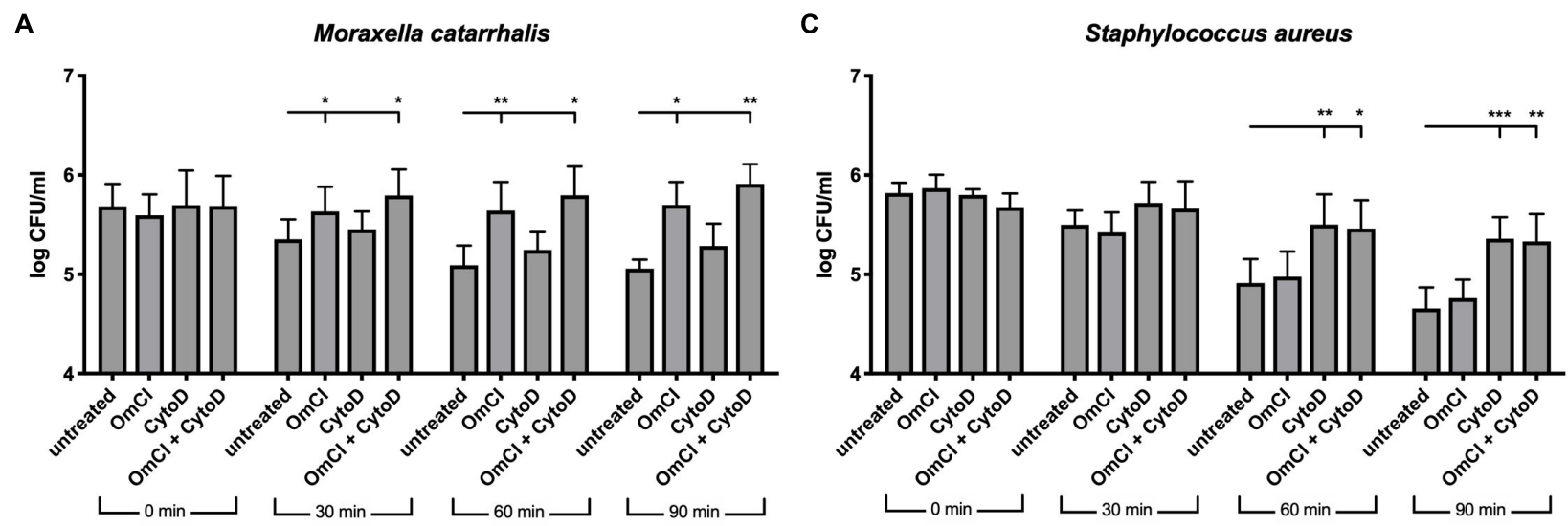

B

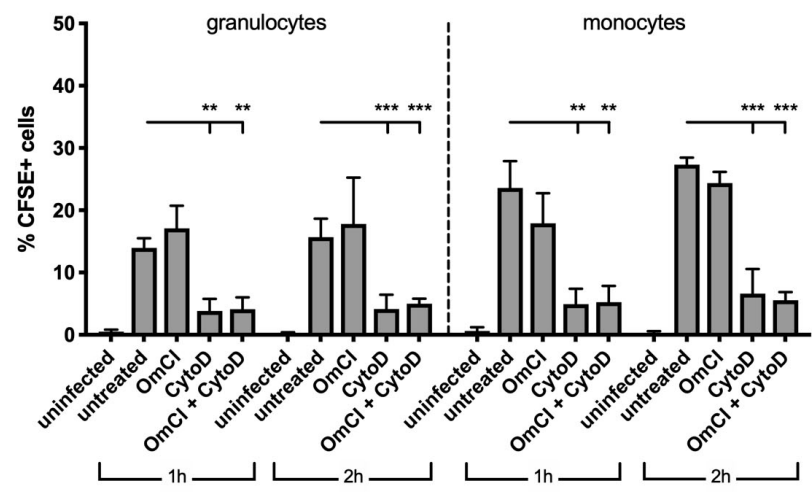

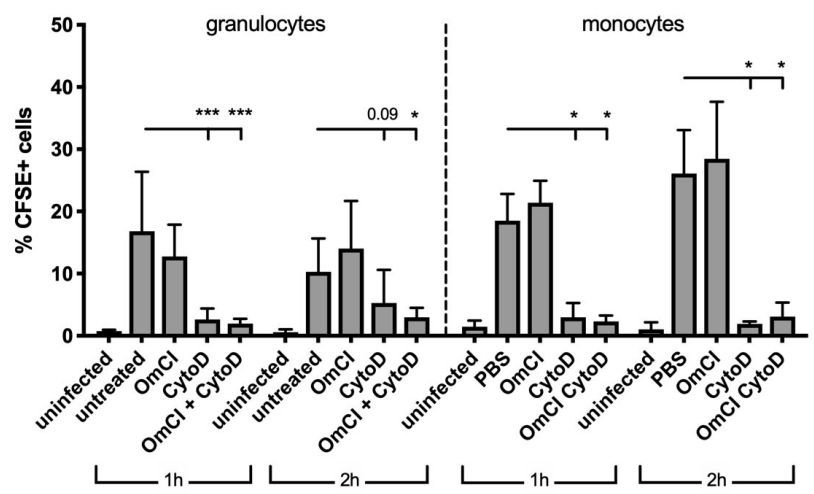

FIGURE 3 | In a whole blood model, M. catarrhalis is killed through MAC-mediated killing. CFSE-labeled bacteria were added to whole blood previously incubated with $1 \mu \mathrm{M} \mathrm{OmCl}, 10 \mu \mathrm{M}$ cytochalasin D or both. (A,B) M. catarrhalis clinical isolate \#473 was picked as more serum resistant than most clinical isolates and the reference strain $\mathrm{RH} 4$ (C,D) Staphylococcus aureus JE2 was used as an example of MAC-resistant bacteria (A,C) Survival of bacteria overtime was assessed by collecting a sample at $t=0,30,60$, and 90 min post-infection, and plating bacteria on agar plates. The number of bacteria is represented as log of CFU/ml. (B,D) Phagocytosis was assessed by detection of CFSE+ cells among granulocytes and monocytes from whole blood. At 1 and $2 \mathrm{~h}$ post-infection, a sample was collected, red blood cells were lysed, cells were fixed and stained with anti-CD14, and cells were analyzed using flow cytometry. The percentage of CFSE+ cells was measured in granulocytes and monocytes (gated using Side Scatter and CD14 staining). Mean ( \pm SD) from four (A) or three (B-D) independent experiments are shown. Statistical significance of differences was calculated using two-way ANOVA with Dunnett's post-test; ${ }^{*} p<0.05 ;{ }^{* *} p<0.01$; and ${ }^{* \star *} p<0.001$.

in an environment containing both complement and phagocytes, M. catarrhalis is killed through MAC-mediated lysis. Based on this, the effect of the fusion proteins in killing M. catarrhalis will be evaluated in serum alone.

Recruitment of $\mathrm{FH}$ and or C4BP to the bacterial surface interferes with complement deposition and contributes to serum resistance. Therefore, we tested the ability of FH6-7/IgG and C4BP1-2/IgM to augment serum killing. Both fusion proteins, when pre-incubated with $M$. catarrhalis at a final fusion protein concentration of $50 \mu \mathrm{g} / \mathrm{ml}$, resulted in a significant reduction in bacterial survival (Figure 4A). C4BP1-2/IgM did not displace serum C4BP (Figure 2C), but still bound bacteria in the presence of serum (Figure 2D), and the hexavalent structure of the C4BP1-2/IgM fusion protein would most likely be a potent activator of the classical pathway of complement, explaining the reduced bacterial survival compared to no protein serum control. Regarding the enhanced FH6-7/IgG-dependent serum killing, both displacement of FH from the bacterial surface and
Fc-mediated activation of the classical pathway were likely to have contributed to enhanced killing.

When fusion proteins were added with bacteria and serum simultaneously we observed a statistically significant decrease in survival with FH6-7/IgG and C4BP1-2/IgM (Figures 4A,B). However, the reduction is less apparent with $\mathrm{C} 4 \mathrm{BP} 1-2 / \operatorname{IgM}$ compared to FH6-7/IgG, likely because the C4BP1-2/IgM fusion protein does not prevent serum $\mathrm{C} 4 \mathrm{BP}$ binding on the bacterial surface. Finally, we confirm that FH6-7/IgG enhances serum killing of strain RH4 in a dose-dependent fashion that requires active complement (Figure 4C).

\section{FH6-7/lgG Enhances C3b and MAC Deposition}

In order to understand how FH6-7/IgG increased serum sensitivity of $M$. catarrhalis we examined the deposition of complement components $\mathrm{iC} 3 \mathrm{~b}, \mathrm{C} 3 \mathrm{~d}$, and MAC in the presence 
A

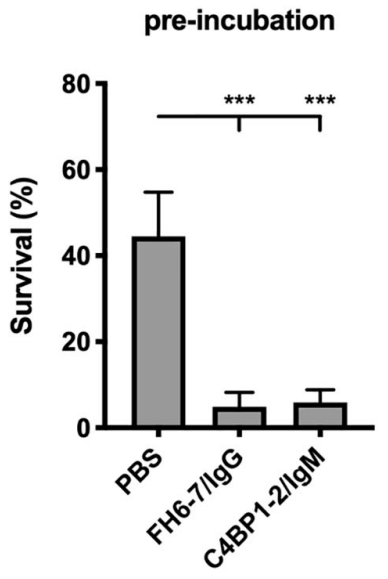

B

simultaneous addition

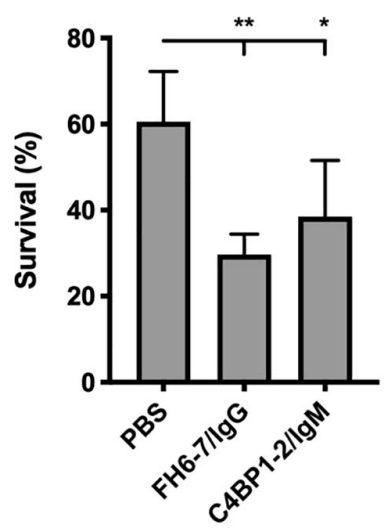

C

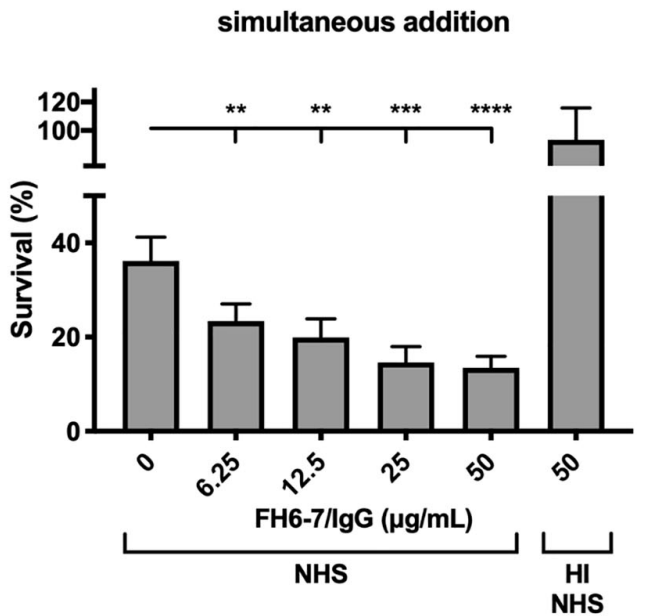

FIGURE 4 | FH6-7/lgG and C4BP1-2/lgM increase serum killing of $M$. catarrhalis. (A) Bacteria were pre-incubated with PBS (control), 50 $\mu$ g/ml of FH6-7/lgG or $50 \mu \mathrm{g} / \mathrm{ml}$ of C4BP1-2/lgM for 30 min before addition of $10 \% \mathrm{NHS}$. Bacteria were counted at $t=0$ and $t=30$ min post-addition of serum and survival percentage was calculated. (B) Fusion proteins and serum were added simultaneously to the bacteria, and bacteria survival was calculated. (C) Increasing amounts of FH6-7/lgG were added simultaneously with NHS to bacteria and survival was calculated. Heat-inactivated NHS was used as a negative control of bacteria killing. Mean $( \pm S D)$ from three $(\mathbf{A}, \mathbf{C})$ or four $(\mathbf{B})$ independent experiments are shown. Statistical significance of differences was calculated using one-way ANOVA with Dunnett's post-test; ${ }^{\star} p<0.05 ;{ }^{\star \star} p<0.01 ;{ }^{* \star *} p<0.001$; and ${ }^{\star \star \star \star} p<0.0001$.

and absence of fusion protein using flow cytometry. We choose to investigate both $\mathrm{iC} 3 \mathrm{~b}$ and $\mathrm{C} 3 \mathrm{~d}$ as markers of $\mathrm{C} 3 \mathrm{~b}$ deposition due to our previous experience with non-specific binding and anomalies with Ab detection of cleaved complement components. In accordance with the serum bactericidal data, the presence of FH6-7/IgG resulted in a significant increase in $\mathrm{iC} 3 \mathrm{~b}, \mathrm{C} 3 \mathrm{~d}$, and MAC deposition compared to no FH6-7/IgG control (Figures 5A-C). In contrast, no significant differences in complement deposition were observed when C4BP1-2/IgM was simultaneously added with serum, likely because this assay is not sensitive enough to detect a smaller increase in complement deposition (Figures 5D-F). However, an increase in complement deposition is observed when bacteria were pre-treated with C4BP1-2/IgM, in accordance with the increase in serum killing (Figures 5G-I).

\section{FH6-7/lgG Binds a Broad Panel of M. catarrhalis Clinical Isolates Resulting in Enhanced Serum Killing}

To ascertain whether FH6-7/IgG could be used as a novel immunotherapeutic we investigated the activity of this fusion protein against a panel of genetically diverse clinical isolates of $M$. catarrhalis. These isolates represent a broad diversity of virulent $M$. catarrhalis strains, and several UspA types: UspA2H (like RH4), UspA2 NTER2A or NTER2B. Both fusion proteins bind RH4 through the adhesin UspA2 (Figures 1E,F), therefore it is of interest to know whether different UspA2 types can also bind FH6-7/IgG and C4BP1-2/IgM. All M. catarrhalis clinical isolates bound $\mathrm{FH6}-7 / \mathrm{IgG}$, similarly to our lab strain RH4, regardless of their UspA type (Figure 6A). This binding of FH6$7 / \mathrm{IgG}$ fusion protein correlated with increased serum killing of a majority of the $M$. catarrhalis clinical isolates independently of their UspA type, when fusion protein and serum were added simultaneously (Figures 6B-D). This shows that FH6-7/IgG could constitute a promising therapeutic strategy in a large number of $M$. catarrhalis infections.

\section{C4BP1-2/lgM Binds a Broad Panel of M. catarrhalis Clinical Isolates Resulting in Enhanced Serum Killing}

Similarly, we next investigated the activity of C4BP1-2/IgM against a collection of genetically diverse $M$. catarrhalis clinical isolates. Surprisingly, all clinical isolates bound C4BP1-2/IgM much less than our reference strain RH4 (Figure 7A). To test whether this lower binding could be due to the fact that these isolates bind C4BP less than RH4, we assessed the binding of C4BP from serum to these isolates. With the exception of KR510, we observed significant correlation between the binding of C4BP1-2/IgM and C4BP from serum (Figure 7B). In addition all clinical isolates bound $\mathrm{C} 4 \mathrm{BP}$ less than the laboratory strain RH4 (Figure 7B). Although KR510 bound the fusion protein poorly, it bound $\mathrm{C} 4 \mathrm{BP}$ very strongly, suggesting that it may bind C4BP through domains other than CCP1 and 2, the only C4BP domains present in the fusion protein. Based on the following observations; (1) C4BP1-2/IgM cannot prevent the binding of C4BP from serum; (2) $M$. catarrhalis clinical isolates bound C4BP1-2/IgM more poorly than RH4; and (3) C4BP1-2/IgM was less efficient at enhancing RH4 serum killing when simultaneously added (Figure 4B); we investigated serum survival of clinical isolates pre-treated with C4BP1-2/IgM. Although clinical isolates bound C4BP1-2/IgM more poorly than RH4, we observed an increased killing of the majority of 
A

AH6-7/lgG
simultaneous addition

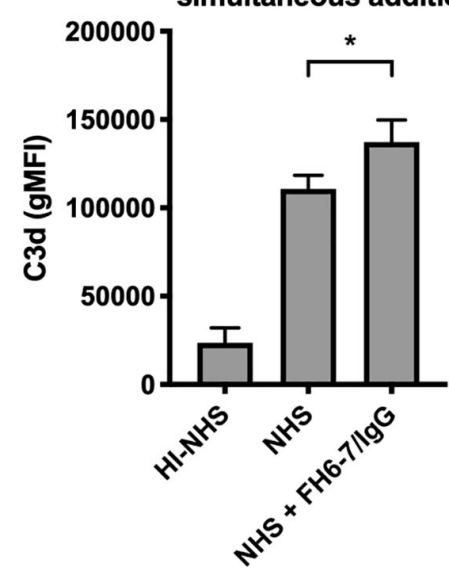

B

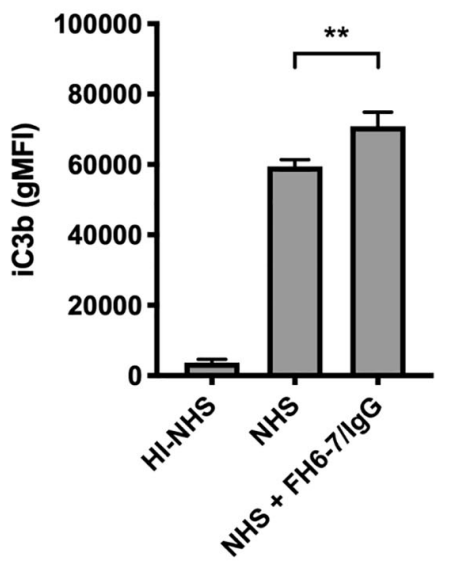

C

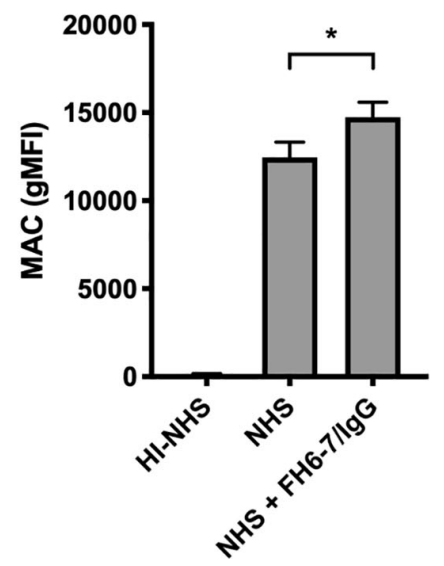

D

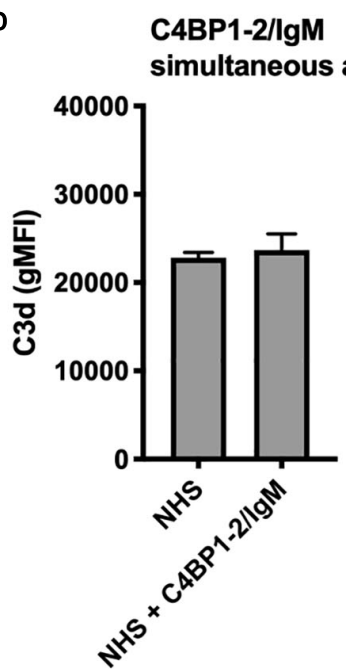

E

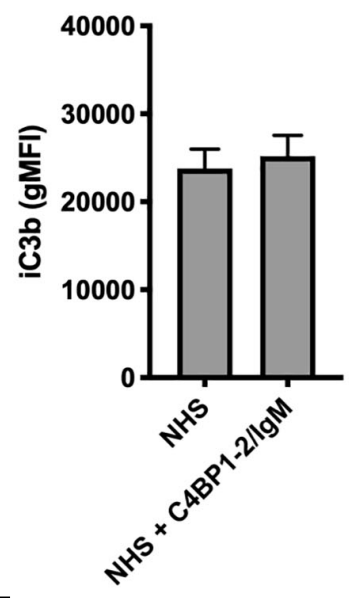

F

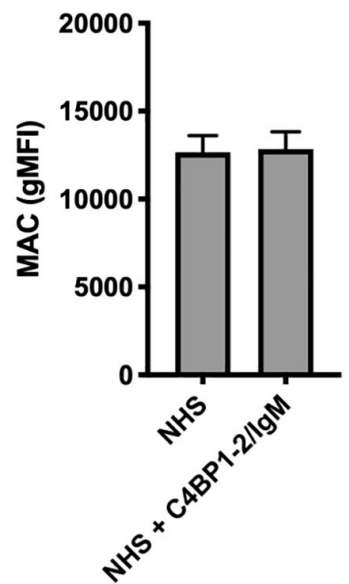

G

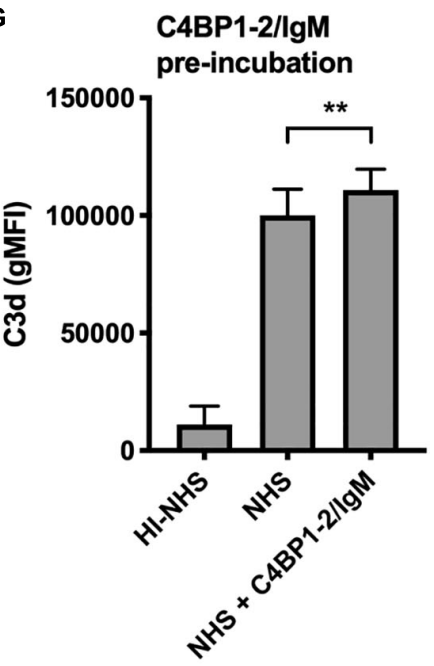

H

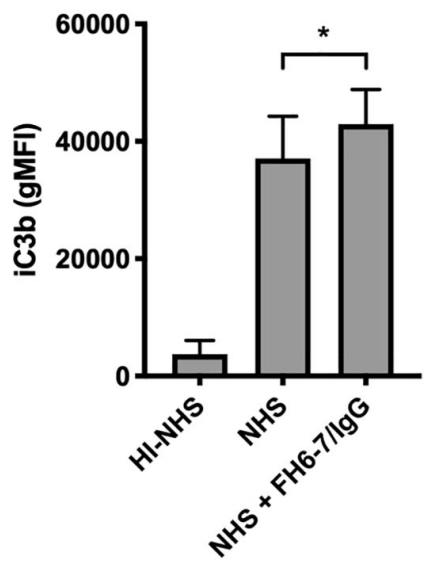

I

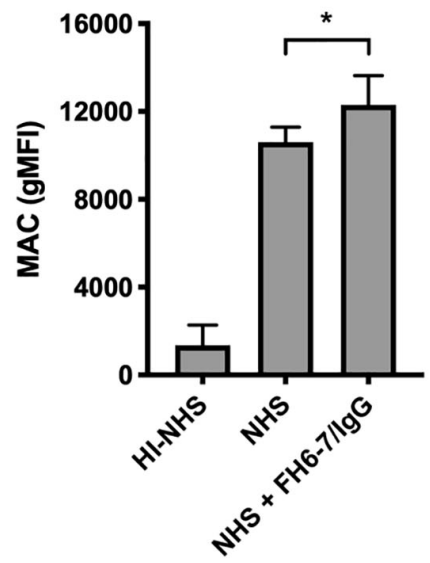

FIGURE 5 | Fusion proteins increase complement deposition on the bacterial surface. Flow cytometry was used to measure C3d, iC3b, and MAC binding at the surface of $M$. catarrhalis. (A-C) FH6-7/lgG and serum were added simultaneously to bacteria. Bacteria were incubated with $5 \%$ OmCl-treated serum for 30 min for C3 deposition, or 10\% NHS for 20 min for MAC deposition. Heat-inactivated serum was used as a negative control of complement activation. (D-F) C4BP1-2/lgM and serum were added simultaneously to bacteria. (G-I) Bacteria were pre-incubated with C4BP1-2/lgM before addition of serum. Mean ( \pm SD) from three (A-F) or four (G-I) independent experiments are shown. Statistical significance of differences was calculated using one-way ANOVA with Dunnett's post-test; ${ }^{*} p<0.05$; ${ }^{* *} p<0.01$ 
A

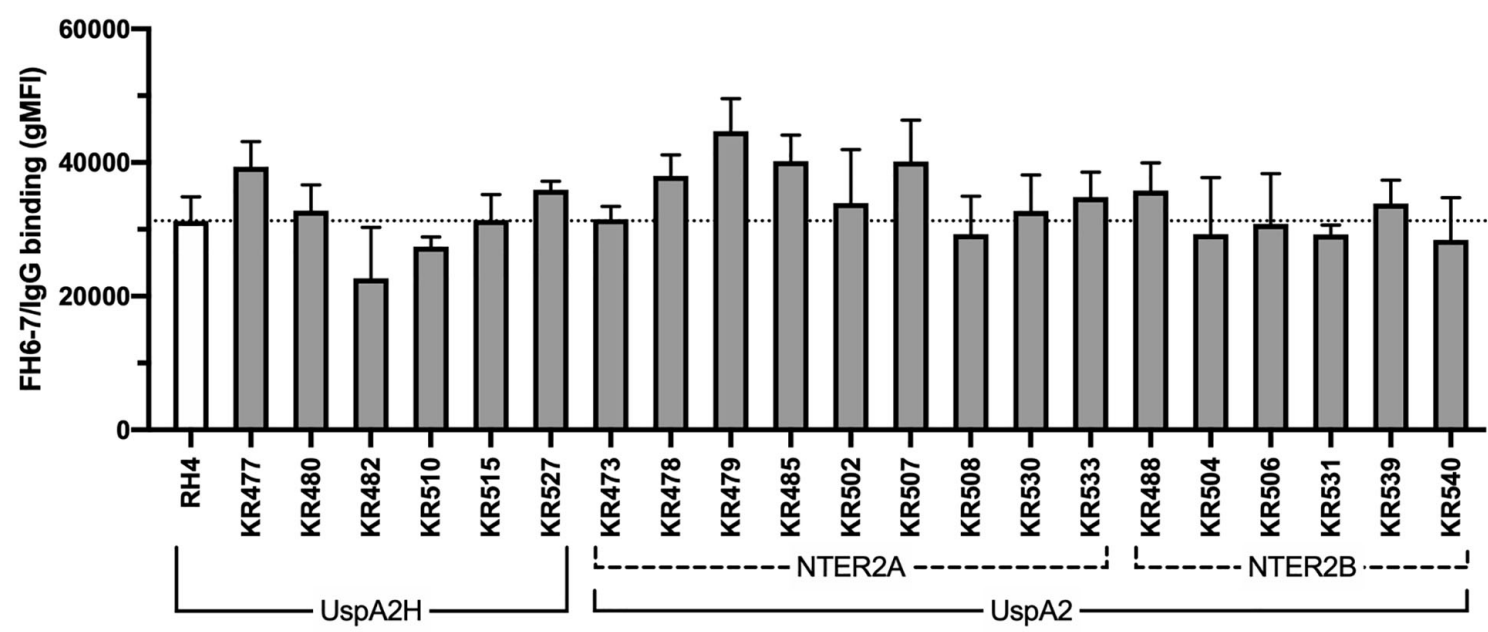

B

UspA2 NTER2A

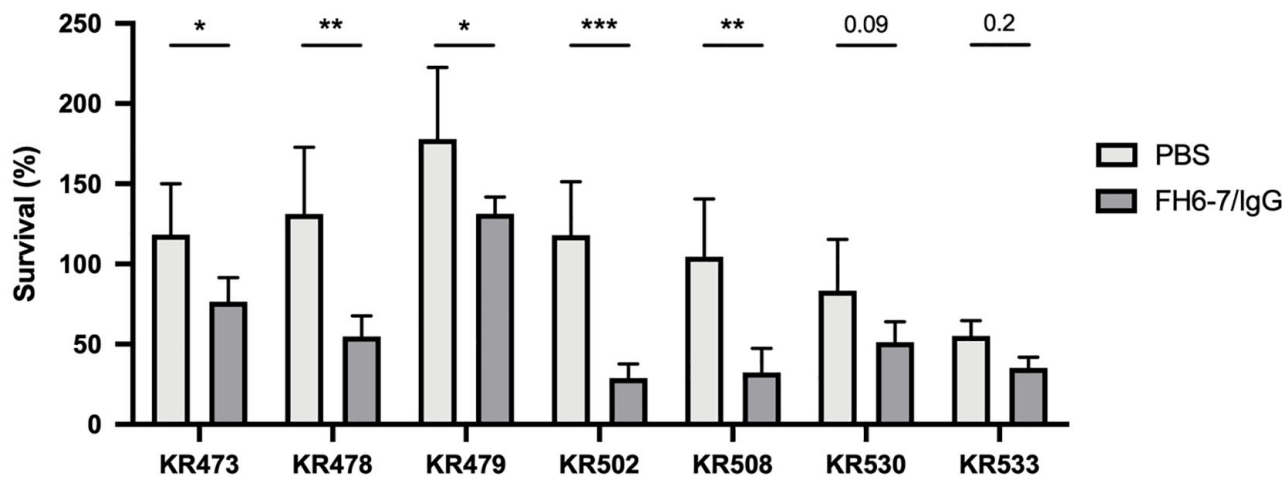

C

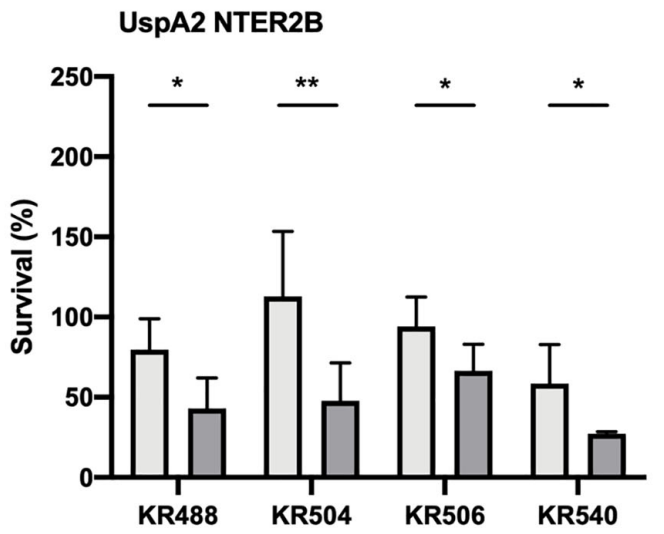

D

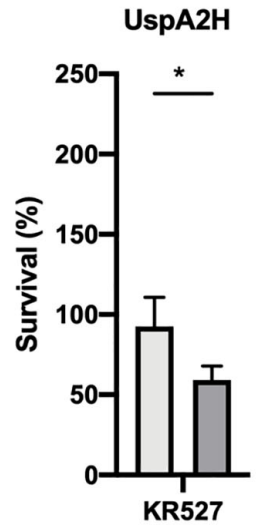

FIGURE 6 | FH6-7/lgG binds to and increases serum killing of a large majority of $M$. catarrhalis clinical isolates. (A) 21 clinical isolates and the laboratory strain RH4 were tested for FH6-7/lgG binding by flow cytometry. In the absence of FH6-7/lgG, bacteria incubated with detection antibody had a similar gMFI for all isolates (average 151, standard deviation 45). (B-D) Twelve clinical isolates were treated with $50 \mu \mathrm{g} / \mathrm{ml}$ of FH6-7/lgG or PBS, at the same time as $15 \%$ NHS, and their survival after 30 min was assessed by plating bacteria and counting remaining colony forming-units (CFU). The remaining nine isolates were not included because their survival in serum in the absence of fusion protein was less than 5\%. (B) UspA2 NTER2A strains, (C) UspA2 NTER2B strains, (D) UspA2H strains. Mean ( \pm SD) from three (A-C) or four (D) independent experiments are shown. Statistical significance of differences was calculated using two-way ANOVA with Holm-Sidak's post-test; ${ }^{\star} p<0.05 ;{ }^{* \star} p<0.01 ;{ }^{\star \star \star} p<0.001$. 
A

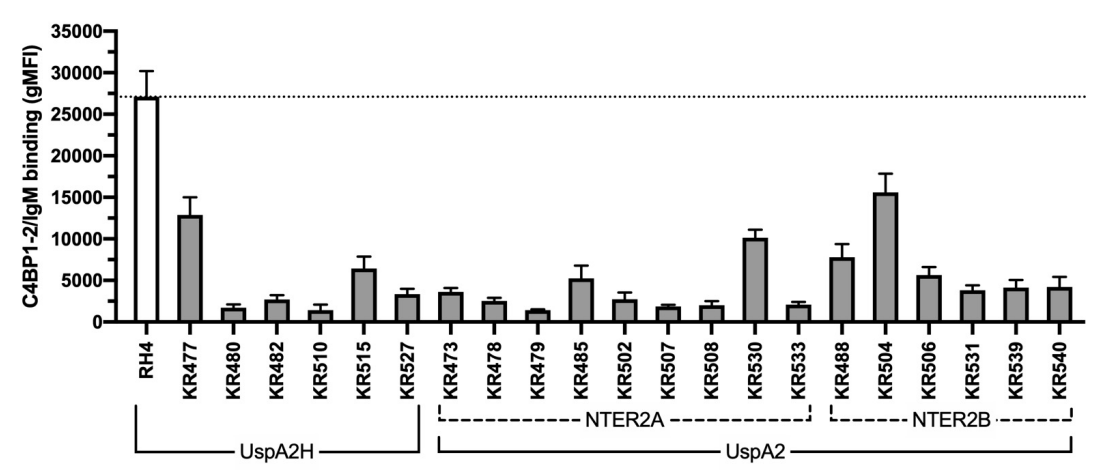

B

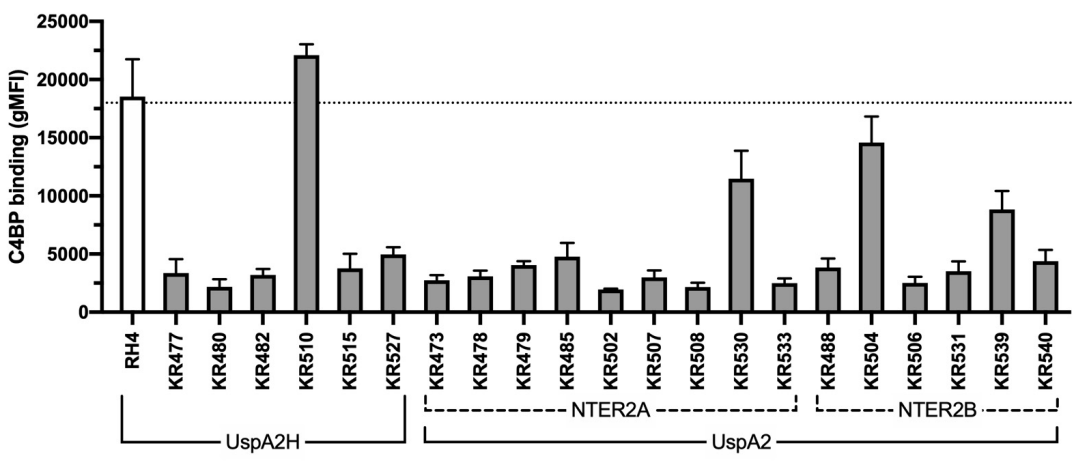

C

UsPA2 NTER2A

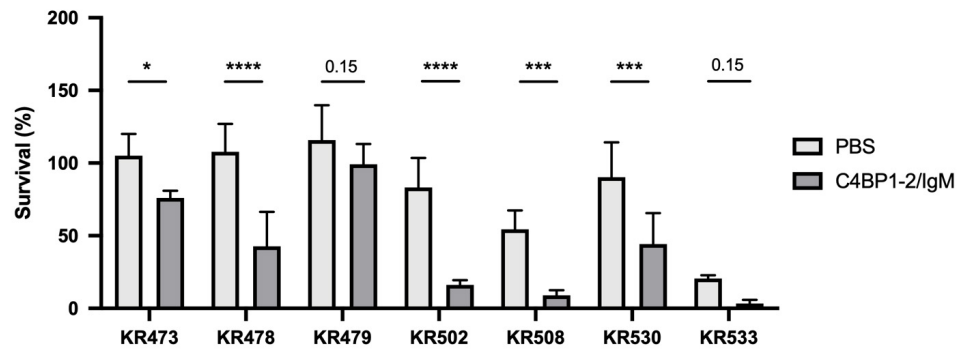

D

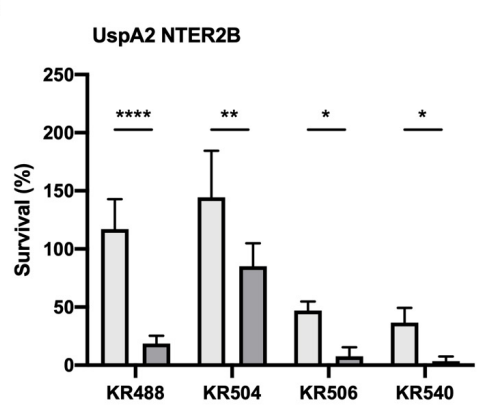

E

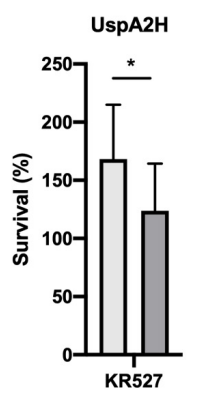

FIGURE 7 | C4BP1-2/lgM binds to and increases serum killing of many of the $M$. catarrhalis clinical isolates tested. (A) 21 clinical isolates and the lab strain RH4 were tested for C4BP1-2/lgM binding by flow cytometry. The gMFI for control without C4BP1-2/lgM was similar in all isolates (average 152, SD 75). (B) Clinical isolates were tested for C4BP binding from NHS by flow cytometry. Moraxella isolates were treated with $5 \% \mathrm{NHS}+\mathrm{OmCl}$ for 30 min. The gMFI for control without NHS was similar in all isolates (average 207, SD 132). (C-E) Twelve clinical isolates were treated with $50 \mu \mathrm{g} / \mathrm{ml}$ of C4BP1-2/lgM or PBS, before addition of as $15 \%$ $\mathrm{NHS}$, and their survival after 30 min was assessed by plating bacteria and counting remaining CFU. The remaining nine isolates were not included because their survival in serum in the absence of fusion protein was less than 5\%. (C) UspA2 NTER2A strains, (D) UspA2 NTER2B strains, (E) UspA2H strains. Mean ( \pm SD) from three (A) or four (B-E) independent experiments are shown. Statistical significance of differences was calculated using two-way ANOVA with Holm-Sidak's post-test; ${ }^{\star} p<0.05 ;{ }^{* *} p<0.01 ;{ }^{* \star *} p<0.001 ;{ }^{* \star *} p<0.0001$. 
M. catarrhalis isolates when they were pretreated with C4BP12/IgM (Figures 7C-E).

\section{DISCUSSION}

The common respiratory pathogen $M$. catarrhalis causes significant morbidity and economic burden because it is responsible for otitis media in children and exacerbations of chronic obstructive pulmonary disease in older individuals (2, 3). Currently, there is no vaccine to prevent $M$. catarrhalis infection. Given that otitis media is the most common reason for which children receive antibiotics (35), treatment of $M$. catarrhalis disease with antibiotics promotes antibiotic resistance and also disrupts normal commensal microbiota (1). Therefore, the development of novel adjunctive anti-infective immunotherapeutics against opportunistic pathogens such as M. catarrhalis would be highly beneficial.

Complement is present and active in both anatomical regions in which M. catarrhalis causes disease. In the ear, complement cleavage activation fragments of $\mathrm{C} 3, \mathrm{C} 4$, and Factor $\mathrm{B}$ have been detected in patients with otitis media with effusions (36). In a separate study, the cytolytic activity and presence of the MAC was observed in middle ear effusions obtained from persistent otitis media infections (37). In addition, C3-coated bacteria were identified in a small number of middle ear exudates originating from children suffering from acute otitis media (38). The role of complement in preventing middle ear infection has been demonstrated. Complement depletion by use of cobra venom factor restored the capacity of two avirulent NTHi strains to cause otitis media in a chinchilla model of infection (39). In the lungs, local synthesis of complement occurs; pulmonary alveolar type II epithelial cells secrete complement proteins C2, C4, C5, and Factor B (40), while bronchiolar epithelial cells generate $\mathrm{C} 3$ and membrane bound complement regulatory proteins (41). Complement components have been detected in bronchial secretions isolated from guinea pigs. Importantly, enhanced titers of complement proteins were observed following intranasal infection of guinea pigs with mycoplasma, indicating a role for complement in tackling lung infections (42). Moreover, intranasal administration of FH6-7/IgG enhanced clearing of NTHi in a mouse model of lung infection highlighting the therapeutic potential of this fusion protein (20).

In this study, we showed that fusion proteins, FH6-7/IgG and C4BP1-2/IgM, constitute novel antimicrobial strategies effective in eliminating $M$. catarrhalis. In particular, FH6-7/IgG bound all tested $M$. catarrhalis clinical strains taken from a cohort of genetically diverse isolates. Importantly, FH6-7/IgG significantly increased serum killing of the vast majority of tested isolates. Our data suggests that enhanced killing was due to a combination of (i) preventing the recruitment of the soluble complement inhibitor FH to the bacterial surface via displacement, while (ii) simultaneously promoting complement deposition by activation of the classical pathway via the exposed IgG Fc region.

Incubation of $M$. catarrhalis with C4BP1-2/IgM also resulted in decreased bacterial survival, although this was less efficient than FH6-7/IgG when added simultaneously with NHS. This is most likely due to the inability of $\mathrm{C} 4 \mathrm{BP} 1-2 / \operatorname{IgM}$ to outcompete and displace $\mathrm{C} 4 \mathrm{BP}$ recruited from serum. We showed that C4BP1-2/IgM interacts with $M$. catarrhalis through UspA2, similarly to C4BP and $\mathrm{FH}$. C4BP is a large glycoprotein containing seven identical alpha chains housing CCP domains, which are integral for complement inhibition (43). Previous work has illustrated that the binding region responsible for UspA2C4BP interaction is localized to the CCP2, CCP5, and CCP7 domains of the alpha chain (24). We show that $M$. catarrhalis has the capacity to concomitantly bind C4BP and C4BP12/IgM. As a result, bound C4BP can continue to inhibit complement activation in the presence of C4BP1-2/IgM, thus preventing significant bacterial killing. Our results suggest that the bactericidal activity of C4BP1-2/IgM depends on which factor, C4BP1-2/IgM or serum derived C4BP, interacts first with the pathogen in vivo, as pre-incubation of the bacterium with C4BP1-2/IgM significantly accelerates serum killing.

Importantly, previous work has shown using ex vivo assay and in vivo animal models that these fusion proteins do not cause unwanted complement activation or tissue damage. Bettoni et al. (19) confirmed that C4BP1-2/IgM does not deposit complement on human erythrocytes or apoptotic cells. Importantly, this fusion protein lacks the CCP 3 domain of C4BP which is required for binding to $\mathrm{C} 4 \mathrm{~b}$ fragments on the cell surface and therefore interaction of $\mathrm{C} 4 \mathrm{BP} 1-2 / \mathrm{IgM}$ with $\mathrm{C} 4 \mathrm{~b}$-decorated cells is prevented. Furthermore, the authors showed that C4BP1$2 / \mathrm{IgM}$ was effective in preventing gonococcal colonization in a mouse vaginal colonization model using human FH/C4BP transgenic mice. Importantly, no adverse side effects following administration of C4BP1-2/IgM to mice was observed over the duration of the experiment. Blom et al. (22) confirmed that FH67/IgG does not enhance classical or AP activation measured via sensitized sheep and rabbit erythrocyte hemolysis assays. In addition, using a platelet aggregation assay, FH6-7/IgG did not activate platelets and no degree of coagulation activation was observed. In addition, FH6-7/IgG was effective in reducing mortality in a streptococcal sepsis model of infection using human FH/C4BP transgenic mice and showed no adverse side effects following administration. Specifically the authors noted no enhanced complement deposition in tissues sections taken from the eyes and kidneys of FH6-7/IgG treated and untreated animals, either infected or not with S. pyogenes (22). Lastly, Shaughnessy et al. (44) also observed no short term renal (increases in creatinine) or hematologic (increases in lactate dehydrogenase or decrease in hematocrit) or adverse side effects following systemic administration of FH6-7/IgG. Although this data is encouraging, future toxicology assessments are required and will take place during the preclinical development of these fusion proteins.

Alternative treatments such as fusion proteins could reduce the use of antibiotics, which are associated with many adverse effects such as the development of antibiotic resistance and the destruction of normal respiratory tract microbiota. Importantly, developing new treatment approaches based on components used by bacteria to confer serum resistance will ease or eliminate the selective pressure required to drive resistance against these therapeutics. We show that binding of both fusion proteins (FH6-7/IgG and C4BP1-2/IgM) to M. catarrhalis relies heavily 
on the expression of Usp proteins, particularly UspA2. UspA2 is a non-fimbrial surface protein (45), highly conserved across disease isolates (46) and expressed during in vivo infection (47). Resistance to fusion proteins would require the emergence of UspA2 null mutants or UspA2 mutants unable to interact with FH6-7 and/or C4BP1-2 domains of circulating FH and $\mathrm{C} 4 \mathrm{BP}$, respectively, resulting in the reduced ability to recruit these soluble regulators. UspA2 plays even more roles in complement evasion as in addition to $\mathrm{FH}$ and C4BP, it also binds vitronectin, a multifunctional glycoprotein which can prevent the formation of MAC on the bacterial surface (32), and plasminogen, a zymogen which when converted to plasmin can degrade central complement components (33). Interaction of UspA2 with these glycoproteins adds extra pressure to maintain the WT UspA2 protein sequence and/or conformation. An inability to bind $\mathrm{C} 4 \mathrm{BP}, \mathrm{FH}$, vitronectin and plasminogen due to loss of UspA2 would pose a significant fitness disadvantage promoting eradication by complement activity $(24,32,48,49)$.

Moraxella catarrhalis is both a normal commensal and a pathogen of the respiratory tract (50), and although little is known about the differences between the two or how it switches from one to the other, preserving the healthy microbiota when targeting pathogenic bacteria is critical. Microbial community composition has a profound impact on human health, protecting against the growth and invasion of respiratory pathogens (51), helping with the development and maintenance of a healthy immune system (52), but also preventing neurological diseases such as Parkinson's disease, Alzheimer's disease, and multiple sclerosis (53). M. catarrhalis strains isolated from patients with bronchopulmonary infection were more resistant to complement-mediated killing than strains harbored by healthy carriers (89\% vs $41.5 \%$ ) (54). Furthermore, clinical studies have revealed that the increased prevalence of $M$. catarrhalis infections in the winter is due to the exposure to reduced environmental temperature in the nasopharynx (cold shock response), which increases the expression of virulence factors, including UspA2 (55). Cold-shocked bacteria therefore can bind more C4BP and $\mathrm{FH}$ through UspA2 and have an increased resistance to complement. Targeting strains that are able to bind complement inhibitors may thereby select between pathogenic strains and strains part of healthy microbiota.

The development of complement-activating antibodies targeting bacteria represents a promising strategy for antibacterial therapies but is limited by the need to raise specific antibodies against conserved, abundant surface proteins, which are expressed during infection. Such ubiquitous protective epitopes are very difficult to identify, because of the considerable antigenic and phase variability between strains within a species. Making monoclonal antibodies that recognize a wide array of strains and are functional is therefore extremely challenging. The fusion proteins outlined in this study bypass this restriction by behaving as soluble complement inhibitor decoys, which are bound by the majority of clinical isolates. Noteworthy, binding of complement inhibitors is an evasion strategy developed by many different pathogens, from fungi such as Aspergillus spp. and Candida albicans (56-58), parasites such as Plasmodium falciparum (59), and many bacterial species. Among these bacteria, FH6-7/IgG fusion protein successfully enhanced the killing of H. influenzae (20), N. meningitidis (18), N. gonorrhoeae (21), and Streptococcus pyogenes (22), while C4BP1-2/IgM strongly enhanced the killing of $N$. gonorrhoeae (19). Therefore, fusion proteins can prove very useful in the treatment of large variety of infections with this study highlighting their effectiveness in enhancing serum killing of $M$. catarrhalis.

\section{CONCLUSION}

In conclusion, we have shown that fusion proteins combining bacteria-binding sequences of complement inhibitors and Fc parts of immunoglobulins constitute a novel therapeutic approach against the human pathogen $M$. catarrhalis. Targeting such a key immune evasion strategy evolved by bacteria allows us to treat infection without triggering antibiotics resistance, and can be extended to a large variety of human pathogens.

\section{DATA AVAILABILITY STATEMENT}

The raw data supporting the conclusions of this article will be made available by the authors, without undue reservation.

\section{ETHICS STATEMENT}

The studies involving human participants were reviewed and approved by the ethical committee in Lund (Permit 2017/582). The patients/participants provided their written informed consent to participate in this study.

\section{AUTHOR CONTRIBUTIONS}

ML, LC, SB, DE, SR, and AB designed the experiments. ML, LC, $\mathrm{SB}$, and $\mathrm{KM}$ conducted the experiments. ML, LC, DE, and $\mathrm{AB}$ analyzed the data. KR provided clinical isolates and mutants. ML, $\mathrm{LC}$, and $\mathrm{AB}$ wrote the manuscript. All authors contributed to the article and approved the submitted version.

\section{FUNDING}

$\mathrm{AB}$ and $\mathrm{KR}$ were supported by the Swedish Research Council (2018-02392 and 2019-01053, respectively), The Söderberg Foundation, The Österlund Foundation. ML was supported by the Lars Hierta's Memorial Foundation (FO2018-0063), the Tore Nilson's Foundation (2017-00519; 2018-00616), the Royal Physiographic Society of Lund and Royal Society, United Kingdom. LC was supported by the Royal Physiographic Society of Lund and the Berth von Kantzows Foundation. SB was supported by Sten K. Johnsons Foundation, the Tore Nilson's Foundation (2019-00750), the Royal Physiographic Society of Lund and the O. E. och Edla Johanssons Foundation. Längmanska kulturfonden (BA20-1272), Thelma Zoegas fondation (TZ2019-0039). SR was supported by National Institutes of Health/National Institutes of Allergy and Infectious Diseases grants AI132296, AI136007, AI114790, and AI147930. 


\section{REFERENCES}

1. Murphy TF, Parameswaran GI. Moraxella catarrhalis, a human respiratory tract pathogen. Clin Infect Dis. (2009) 49:124-31. doi: 10.1086/599375

2. Su YC, Singh B, Riesbeck K. Moraxella catarrhalis: from interactions with the host immune system to vaccine development. Future Microbiol. (2012) 7:1073-100. doi: $10.2217 /$ fmb. 12.80

3. Murphy TF, Brauer AL, Grant BJ, Sethi S. Moraxella catarrhalis in chronic obstructive pulmonary disease: burden of disease and immune response. Am J Respir Crit Care Med. (2005) 172:195-9. doi: 10.1164/rccm.200412-1747OC

4. Funaki T, Inoue E, Miyairi I. Clinical characteristics of the patients with bacteremia due to Moraxella catarrhalis in children: a case-control study. BMC Infect Dis. (2016) 16:73. doi: 10.1186/s12879-016-1408-3

5. Merle NS, Church SE, Fremeaux-Bacchi V, Roumenina LT. Complement system part i-molecular mechanisms of activation and regulation. Front Immunol. (2015) 6:262. doi: 10.3389/fimmu.2015.00262

6. Berends ET, Kuipers A, Ravesloot MM, Urbanus RT, Rooijakkers SH. Bacteria under stress by complement and coagulation. FEMS Microbiol Rev. (2014) 38:1146-71. doi: 10.1111/1574-6976.12080

7. Kishore U, Reid KB. C1q: structure, function, and receptors. Immunopharmacology. (2000) 49:159-70. doi: 10.1016/S0162-3109(00) 80301-X

8. Le Cabec V, Carreno S, Moisand A, Bordier C, Maridonneau-Parini I. Complement receptor $3(\mathrm{CD} 11 \mathrm{~b} / \mathrm{CD} 18)$ mediates type I and type II phagocytosis during nonopsonic and opsonic phagocytosis, respectively. $J$ Immunol. (2002) 169:2003-9. doi: 10.4049/jimmunol.169.4.2003

9. Noris M, Remuzzi G. Overview of complement activation and regulation. Semin Nephrol. (2013) 33:479-92. doi: 10.1016/j.semnephrol.2013.08.001

10. de Cordoba SR, Esparza-Gordillo J, de Jorge EG, Lopez-Trascasa M, SanchezCorral P. The human complement factor $\mathrm{H}$ : functional roles, genetic variations and disease associations. Mol Immunol. (2004) 41:355-67.

11. Ermert D, Blom AM. C4b-binding protein: the good, the bad and the deadly. novel functions of an old friend. Immunol Lett. (2016) 169:82-92. doi: 10. 1016/j.imlet.2015.11.014

12. Blom AM, Kask L, Dahlback B. CCP1-4 of the C4b-binding protein alphachain are required for factor I mediated cleavage of complement factor C3b. Mol Immunol. (2003) 39:547-56. doi: 10.1016/S0161-5890(02)00213-4

13. Blom AM, Hallstrom T, Riesbeck K. Complement evasion strategies of pathogens-acquisition of inhibitors and beyond. Mol Immunol. (2009) 46:2808-17. doi: 10.1016/j.molimm.2009.04.025

14. Laabei M, Ermert D. Catch me if you can: Streptococcus pyogenes complement evasion strategies. J Innate Immun. (2019) 11:3-12. doi: 10.1159/000492944

15. Ermert D, Ram S, Laabei M. The hijackers guide to escaping complement: lessons learned from pathogens. Mol Immunol. (2019) 114:49-61. doi: 10. 1016/j.molimm.2019.07.018

16. Hovingh ES, van den Broek B, Jongerius I. Hijacking complement regulatory proteins for bacterial immune evasion. Front Microbiol. (2016) 7:2004. doi: 10.3389/fmicb.2016.02004

17. Shlaes DM, Sahm D, Opiela C, Spellberg B. The FDA reboot of antibiotic development. Antimicrob Agents Chemother. (2013) 57:4605-7. doi: 10.1128/ AAC.01277-13

18. Shaughnessy J, Vu DM, Punjabi R, Serra-Pladevall J, DeOliveira RB, Granoff $\mathrm{DM}$, et al. Fusion protein comprising factor $\mathrm{H}$ domains 6 and 7 and human IgG1 Fc as an antibacterial immunotherapeutic. Clin Vaccine Immunol. (2014) 21:1452-9. doi: 10.1128/CVI.00444-14

19. Bettoni S, Shaughnessy J, Maziarz K, Ermert D, Gulati S, Zheng B, et al. C4BPIgM protein as a novel therapeutic approach to treat Neisseria gonorrhoeae infections. JCI Insight. (2019) 4:e131886. doi: 10.1172/jci.insight.131886

20. Wong SM, Shaughnessy J, Ram S, Akerley BJ. Defining the binding region in factor $\mathrm{H}$ to develop a therapeutic factor $\mathrm{H}-\mathrm{Fc}$ fusion protein against nontypeable Haemophilus influenzae. Front Cell Infect Microbiol. (2016) 6:40. doi: 10.3389/fcimb.2016.00040

21. Shaughnessy J, Gulati S, Agarwal S, Unemo M, Ohnishi M, Su XH, et al. A novel factor $\mathrm{H}-\mathrm{Fc}$ chimeric immunotherapeutic molecule against Neisseria gonorrhoeae. J Immunol. (2016) 196:1732-40. doi: 10.4049/jimmunol. 1500292

22. Blom AM, Magda M, Kohl L, Shaughnessy J, Lambris JD, Ram S, et al. Factor $\mathrm{H}-\mathrm{IgG}$ chimeric proteins as a therapeutic approach against the gram-positive bacterial pathogen Streptococcus pyogenes. J Immunol. (2017) 199:3828-39. doi: 10.4049/jimmunol.1700426

23. Forsgren A, Brant M, Mollenkvist A, Muyombwe A, Janson H, Woin N, et al. Isolation and characterization of a novel IgD-binding protein from Moraxella catarrhalis. J Immunol. (2001) 167:2112-20. doi: 10.4049/jimmunol.167.4. 2112

24. Nordstrom T, Blom AM, Forsgren A, Riesbeck K. The emerging pathogen Moraxella catarrhalis interacts with complement inhibitor C4b binding protein through ubiquitous surface proteins A1 and A2. J Immunol. (2004) 173:4598-606. doi: 10.4049/jimmunol.173.7.4598

25. Su YC, Hallstrom BM, Bernhard S, Singh B, Riesbeck K. Impact of sequence diversity in the Moraxella catarrhalis UspA2/UspA2H head domain on vitronectin binding and antigenic variation. Microbes Infect. (2013) 15:375-87. doi: 10.1016/j.micinf.2013.02.004

26. Laabei M, Liu G, Ermert D, Lambris JD, Riesbeck K, Blom AM. Short leucinerich proteoglycans modulate complement activity and increase killing of the respiratory pathogen Moraxella catarrhalis. J Immunol. (2018) 201:2721-30. doi: 10.4049/jimmunol.1800734

27. World Medical Association. World medical association declaration of Helsinki: ethical principles for medical research involving human subjects. JAMA. (2013) 310:2191-4. doi: 10.1001/jama.2013.281053

28. Nunn MA, Sharma A, Paesen GC, Adamson S, Lissina O, Willis AC, et al. Complement inhibitor of $\mathrm{C} 5$ activation from the soft tick Ornithodoros moubata. J Immunol. (2005) 174:2084-91. doi: 10.4049/jimmunol.174.4.2084

29. Hardig Y, Hillarp A, Dahlback B. The amino-terminal module of the C4bbinding protein alpha-chain is crucial for $\mathrm{C} 4 \mathrm{~b}$ binding and factor I-cofactor function. Biochem J. (1997) 323(Pt 2):469-75. doi: 10.1042/bj3230469

30. Bernhard S, Fleury C, Su YC, Zipfel PF, Koske I, Nordstrom T, et al. Outer membrane protein OlpA contributes to Moraxella catarrhalis serum resistance via interaction with factor $\mathrm{H}$ and the alternative pathway. J Infect Dis. (2014) 210:1306-10. doi: 10.1093/infdis/jiu241

31. Cope LD, Lafontaine ER, Slaughter CA, Hasemann CA Jr., Aebi C, Henderson FW, et al. Characterization of the Moraxella catarrhalis uspA1 and uspA2 genes and their encoded products. J Bacteriol. (1999) 181:4026-34. doi: 10. 1128/JB.181.13.4026-4034.1999

32. Singh B, Blom AM, Unal C, Nilson B, Morgelin M, Riesbeck K. Vitronectin binds to the head region of Moraxella catarrhalis ubiquitous surface protein A2 and confers complement-inhibitory activity. Mol Microbiol. (2010) 75:142644. doi: 10.1111/j.1365-2958.2010.07066.x

33. Singh B, Al-Jubair T, Voraganti C, Andersson T, Mukherjee O, Su YC, et al. Moraxella catarrhalis binds plasminogen to evade host innate immunity. Infect Immun. (2015) 83:3458-69. doi: 10.1128/IAI.00310-15

34. Heesterbeek DAC, Angelier ML, Harrison RA, Rooijakkers SHM. Complement and bacterial infections: from molecular mechanisms to therapeutic applications. J Innate Immun. (2018) 10:455-64. doi: 10.1159/000491439

35. Siddiq S, Grainger J. The diagnosis and management of acute otitis media: American academy of pediatrics guidelines 2013. Arch Dis Child Educ Pract Ed. (2015) 100:193-7. doi: 10.1136/archdischild-2013-305550

36. Bernstein JM, Schenkein HA, Genco RJ, Bartholomew WR. Complement activity in middle ear effusions. Clin Exp Immunol. (1978) 33:340-6.

37. Narkio-Makela M, Meri S. Cytolytic complement activity in otitis media with effusion. Clin Exp Immunol. (2001) 124:369-76. doi: 10.1046/j.1365-2249. 2001.01523.x

38. Stenfors LE, Raisanen S. Opsonization of middle ear bacteria during chronic suppurative and secretory otitis media. Acta Otolaryngol. (1992) 112:96-101. doi: 10.3109/00016489209100789

39. Figueira MA, Ram S, Goldstein R, Hood DW, Moxon ER, Pelton SI. Role of complement in defense of the middle ear revealed by restoring the virulence of nontypeable Haemophilus influenzae siaB mutants. Infect Immun. (2007) 75:325-33. doi: 10.1128/IAI.01054-06

40. Strunk RC, Eidlen DM, Mason RJ. Pulmonary alveolar type II epithelial cells synthesize and secrete proteins of the classical and alternative complement pathways. J Clin Invest. (1988) 81:1419-26. doi: 10.1172/JCI113472

41. Varsano S, Kaminsky M, Kaiser M, Rashkovsky L. Generation of complement C3 and expression of cell membrane complement inhibitory proteins by human bronchial epithelium cell line. Thorax. (2000) 55:364-9. doi: 10.1136/ thorax.55.5.364 
42. Loos M, Brunner H. Complement components (C1, C2, C3, C4) in bronchial secretions after intranasal infection of guinea pigs with Mycoplasma pneumoniae: dissociation of unspecific and specific defense mechanisms. Infect Immun. (1979) 25:583-5. doi: 10.1128/IAI.25.2.583-585.1979

43. Blom AM, Villoutreix BO, Dahlback B. Functions of human complement inhibitor C4b-binding protein in relation to its structure. Arch Immunol Ther Exp (Warsz). (2004) 52:83-95.

44. Shaughnessy J, Lewis LA, Zheng B, Carr C, Bass I, Gulati S, et al. Human Factor $\mathrm{H}$ domains 6 and 7 Fused to IgG1 Fc Are Immunotherapeutic against Neisseria gonorrhoeae. J Immunol. (2018) 201:2700-9. doi: 10.4049/jimmunol.1701666

45. Hoiczyk E, Roggenkamp A, Reichenbecher M, Lupas A, Heesemann J. Structure and sequence analysis of Yersinia YadA and Moraxella UspAs reveal a novel class of adhesins. EMBO J. (2000) 19:5989-99. doi: 10.1093/emboj/19. 22.5989

46. Meier PS, Troller R, Grivea IN, Syrogiannopoulos GA, Aebi C. The outer membrane proteins UspA1 and UspA2 of Moraxella catarrhalis are highly conserved in nasopharyngeal isolates from young children. Vaccine. (2002) 20:1754-60. doi: 10.1016/S0264-410X(02)00030-0

47. Murphy TF, Brauer AL, Aebi C, Sethi S. Identification of surface antigens of Moraxella catarrhalis as targets of human serum antibody responses in chronic obstructive pulmonary disease. Infect Immun. (2005) 73:3471-8. doi: 10.1128/IAI.73.6.3471-3478.2005

48. Attia AS, Lafontaine ER, Latimer JL, Aebi C, Syrogiannopoulos GA, Hansen EJ. The UspA2 protein of Moraxella catarrhalis is directly involved in the expression of serum resistance. Infect Immun. (2005) 73:2400-10. doi: 10. 1128/IAI.73.4.2400-2410.2005

49. Attia AS, Ram S, Rice PA, Hansen EJ. Binding of vitronectin by the Moraxella catarrhalis UspA2 protein interferes with late stages of the complement cascade. Infect Immun. (2006) 74:1597-611. doi: 10.1128/IAI.74.3.1597-1611. 2006

50. Aebi C. Moraxella catarrhalis-pathogen or commensal? Adv Exp Med Biol. (2011) 697:107-16. doi: 10.1007/978-1-4419-7185-2_9

51. Khan R, Petersen FC, Shekhar S. Commensal bacteria: an emerging player in defense against respiratory pathogens. Front Immunol. (2019) 10:1203. doi: 10.3389/fimmu.2019.01203

52. Kumpitsch C, Koskinen K, Schopf V, Moissl-Eichinger C. The microbiome of the upper respiratory tract in health and disease. BMC Biol. (2019) 17:87. doi: 10.1186/s12915-019-0703-z

53. Bell JS, Spencer JI, Yates RL, Yee SA, Jacobs BM, DeLuca GC. Invited review: from nose to gut-the role of the microbiome in neurological disease. Neuropathol Appl Neurobiol. (2019) 45:195-215. doi: 10.1111/nan. 12520

54. Hol C, Verduin CM, Van Dijke EE, Verhoef J, Fleer A, van Dijk H. Complement resistance is a virulence factor of Branhamella (Moraxella) catarrhalis. FEMS Immunol Med Microbiol. (1995) 11:207-11. doi: 10.1111/ j.1574-695X.1995.tb00118.x

55. Spaniol V, Troller R, Aebi C. Physiologic cold shock increases adherence of Moraxella catarrhalis to and secretion of interleukin 8 in human upper respiratory tract epithelial cells. J Infect Dis. (2009) 200:1593-601. doi: 10. $1086 / 644640$

56. Vogl G, Lesiak I, Jensen DB, Perkhofer S, Eck R, Speth C, et al. Immune evasion by acquisition of complement inhibitors: the mould Aspergillus binds both factor H and C4b binding protein. Mol Immunol. (2008) 45:1485-93. doi: 10.1016/j.molimm.2007.08.011

57. Meri T, Blom AM, Hartmann A, Lenk D, Meri S, Zipfel PF. The hyphal and yeast forms of Candida albicans bind the complement regulator C4b-binding protein. Infect Immun. (2004) 72:6633-41. doi: 10.1128/IAI.72.11.6633-6641. 2004

58. Meri T, Hartmann A, Lenk D, Eck R, Wurzner R, Hellwage J, et al. The yeast Candida albicans binds complement regulators factor $\mathrm{H}$ and FHL-1. Infect Immun. (2002) 70:5185-92. doi: 10.1128/IAI.70.9.5185-5192.2002

59. Kennedy AT, Schmidt CQ, Thompson JK, Weiss GE, Taechalertpaisarn T, Gilson PR, et al. Recruitment of Factor $\mathrm{H}$ as a novel complement evasion strategy for blood-stage plasmodium falciparum infection. J Immunol. (2016) 196:1239-48. doi: 10.4049/jimmunol.1501581

Conflict of Interest: The authors declare that the research was conducted in the absence of any commercial or financial relationships that could be constructed as a potential conflict of interest.

The reviewer EV declared a past co-authorship with one of the authors $\mathrm{AB}$ to the handling editor.

Copyright (C) 2020 Laabei, Colineau, Bettoni, Maziarz, Ermert, Riesbeck, Ram and Blom. This is an open-access article distributed under the terms of the Creative Commons Attribution License (CC BY). The use, distribution or reproduction in other forums is permitted, provided the original author(s) and the copyright owner(s) are credited and that the original publication in this journal is cited, in accordance with accepted academic practice. No use, distribution or reproduction is permitted which does not comply with these terms. 